\title{
Mechanistic investigations of antitumor activity of a Rhodamine B-oleanolic acid derivative bioconjugate
}

\author{
IOANA MACAȘOI ${ }^{1}$, IOANA ZINUCA PAVEL ${ }^{2}$, ALINA ELENA MOACĂ ${ }^{1}$, ȘTEFANA AVRAM $^{2}$, \\ VLAD LAURENȚIU DAVID ${ }^{3}$, DORINA CORICOVAC ${ }^{1}$, ALEXANDRA MIOC $^{4}$, DEMETRIOS A. SPANDIDOS $^{5}$, \\ ARISTIDIS TSATSAKIS ${ }^{6}$, CODRUȚA ȘOICA ${ }^{7}$, VICTOR DUMITRAȘCU ${ }^{8}$ and CRISTINA DEHELEAN ${ }^{1}$ \\ Departments of ${ }^{1}$ Toxicology and Drug Industry, and ${ }^{2}$ Pharmacognosy, Faculty of Pharmacy; \\ ${ }^{3}$ Department of Pediatric Surgery and Orthopedics, Faculty of Medicine; ${ }^{4}$ Department of Anatomy, \\ Physiology and Pathophysiology, Faculty of Pharmacy, 'Victor Babes', University of Medicine and Pharmacy, \\ 300041 Timisoara, Romania; 5 Laboratory of Clinical Virology, Medical School, University of Crete, 70013 Heraklion; \\ ${ }^{6}$ Department of Forensic Sciences and Toxicology, Faculty of Medicine, University of Crete, 71003 Heraklion, \\ Greece; ${ }^{7}$ Department of Pharmaceutical Chemistry, Faculty of Pharmacy; ${ }^{8}$ Department of Pharmacology, \\ Faculty of Medicine, 'Victor Babes', University of Medicine and Pharmacy, 300041 Timisoara, Romania
}

Received May 19, 2020; Accepted June 23, 2020

DOI: $10.3892 / o r .2020 .7666$

\begin{abstract}
Cancer remains a major health problem worldwide due to its high mortality rate. New therapeutic options highlight the importance of discovering new compounds that target the tumor microenvironment, interrupt angiogenesis and act selectively. The present study assessed the antitumor effect and investigated the mechanism of action of a rhodamine B-conjugated oleanolic acid derivative (RhodOA). Consequently, the compound was tested on different human tumor cell lines (A375 melanoma, A549 lung adenocarcinoma and MDA-MB-231 breast adenocarcinoma) and on a non-tumor cell line HaCaT human keratinocyte. RhodOA produced a dose-dependent decrease in tumor cell viability especially in the melanoma cells while affecting the keratinocytes less. In melanoma cells, RhodOA reduced cell migration and produced condensation of cell nuclei and of actin fibers. Furthermore, an impairment in melanoma cell mitochondrial function was observed, while the mitochondrial function of keratinocytes was left intact. In the in ovo chorioallantoic
\end{abstract}

Correspondence to: $\mathrm{Dr}$ Alexandra Mioc, Department of Anatomy, Physiology and Pathophysiology, Faculty of Pharmacy, 'Victor Babes', University of Medicine and Pharmacy, 2nd Eftimie Murgu Sq, 300041 Timisoara, Romania

E-mail: alexandra.petrus@umft.ro

Dr Dorina Coricovac, Department of Toxicology and Drug Industry, Faculty of Pharmacy, 'Victor Babes', University of Medicine and Pharmacy, 2nd Eftimie Murgu Sq, 300041 Timisoara, Romania E-mail: dorinacoricovac@umft.ro

Key words: Rhodamine B-oleanolic acid derivative bioconjugate, melanoma, mitochondrial function, chorioalantoid membrane, immunofluorescence, cytotoxicity membrane model, RhodOA elicited antiangiogenic effect, without showing irritation effect on the membrane. The study provides information on the selective antitumor effect of the derivative and its ability to inhibit cellular respiration, therefore RhodOA can be classified as 'MITOCAN'.

\section{Introduction}

Cancer remains a challenging public health issue due to its high mortality rate. Statistics show that in 2018 over 3 million new cancer cases and more than one million cancer-related deaths were recorded in Europe (1). Research in the field currently focuses on finding new anti-tumor therapies with minimal adverse effects, one of the main research directions consisting of exploitation of natural occurring compounds. While conventional cancer treatment is associated with immunosuppression and the occurrence of infections, new targeted antitumor therapies induce other severe side effects such as inflammation and autoimmunity (2). Therefore, the struggle to find new therapeutic approaches with high selectivity and targeted action is imperative in order to reduce the occurrence of systemic toxic effects.

Recently, the scientific interest has focused on the study of pentacyclic triterpene derivatives, due to their immense therapeutic potential. Oleanolic acid (OA) (Fig. 1), a pentacyclic triterpenoid widely found in plants, whose cytotoxic effect has been tested in numerous tumor cell lines, such as lung cancer (3), breast cancer (4), colon cancer (5) and melanoma cell lines (6), is considered a promising anticancer drug. Insights have been gained with regard to the complexity of mechanisms underlying the antitumor effect of OA, as follows: i) induction of an increased expression of p53 tumor protein, cytochrome $c$, caspase-3 apoptosis-promoting protein and Bax; ii) triggering of mitochondrial mediated apoptosis; iii) inhibition of Akt, mTOR and $\mathrm{S} 6 \mathrm{~K}$ protein expression; iv) cell cycle arrest in different phases in a cancer type-depen- 
dent manner by altering the expression of regulatory cell cycle proteins (7-9); v) antioxidant activity by exerting scavenging effect against superoxide anion, hydroxyl radical, nitric oxide and hydrogen peroxide and also by increasing the ferrous iron chelating activity (10); and vi) inhibition of angiogenesis in a dose- dependent manner (11).

Even though OA has proven potent antitumor activity, the in vivo application is limited due to its very low solubility in aqueous solutions, inconvenience that led to the development of novel semisynthetic derivatives with superior antitumor activity and increased solubility, as: 3- $O$-acetyl-OA derived carboxamides, and oleanolic acid-rhodamine $\mathrm{B}$ derivatives (12-15).

Rhodamines are xanthene-based derivatives widely used as fluorescent dyes for cellular and mitochondrial membrane potential measurement (16). Moreover, rhodamines were shown to penetrate the mitochondrial membrane and to accumulate in this organelle, exhibiting high tumor cell selectivity $(17,18)$. Sommerwerk et al $(12)$ found that the chemical modification of triterpenoic acid derivatives covalently bonded to rhodamine $\mathrm{B}$, including oleanolic acid-rhodamine B derivatives (RhodOA), significantly improves their cytotoxic effect, becoming effective on tumor lines starting at nanomolar (nM) concentrations. Moreover, by staining and double-staining experiments it was reported that a diacetylated maslinic acid derivative, was able to enter the mitochondria, thus presenting a 'MITOCAN' behavior (i.e., agents that directly target and alter mitochondrial function of cancer cells causing cancer cell growth inhibition or apoptosis) (12).

A growing body of literature highlights the essential role that mitochondria play in cancer formation, progression, malignant transformation and even response to treatment $(19,20)$. Due to their involvement in energy production, macromolecule biosynthesis, redox homeostasis, reactive oxygen species (ROS) generation and the process of cell death mitochondria have emerged as promising targets for the anticancer agents $(21,22)$.

Following the findings stated above, the purpose of the present study was to assess the in vitro and in ovo biological activity of RhodOA (Fig. 2) in different human tumor and healthy cell lines (A375 melanoma cell line, MDA-MB-231 breast adenocarcinoma, A549 lung adenocarcinoma, and HaCaT-healthy immortalized keratinocytes) in order to gain a deeper insight regarding their antiproliferative molecular mechanism.

\section{Materials and methods}

Cell culture. A375 human melanoma, A549 human lung adenocarcinoma, and MDA-MB-231 human breast adenocarcinoma cell lines were purchased from the American Type Culture Collection (ATCC); HaCaT-human immortalized keratinocyte cell line was provided by the University of Debrecen, Hungary as a kind gift.

All the cell lines were cultured in Dulbecco's modified Eagle's medium (DMEM; Sigma-Aldrich; Merck KGaA) high-glucose medium supplemented with $10 \%$ fetal bovine serum (FBS; Gibco; Thermo Fisher Scientific, Inc.) and $1 \%$ penicillin/Strep, 10,000 IU/ml (Sigma-Aldrich; Merck

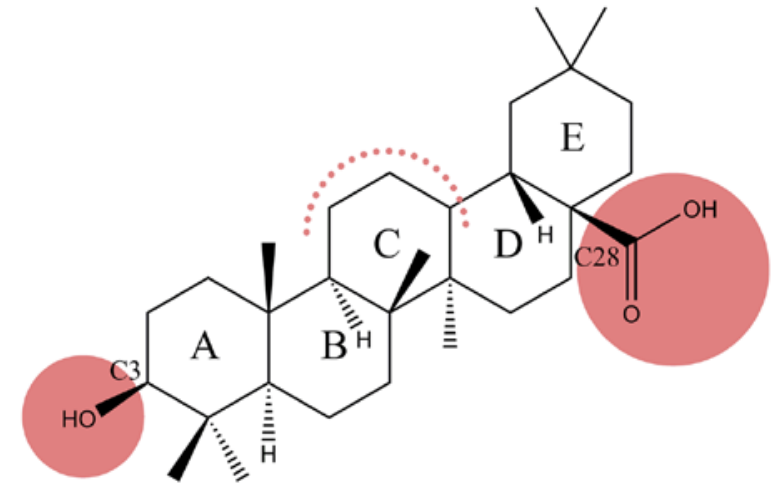

Figure 1. Chemical structure of oleanolic acid (possible derivatization sites highlighted in red).

$\mathrm{KGaA})$. The cells were incubated under standard temperature conditions of $37^{\circ} \mathrm{C}$ and humidity containing $5 \% \mathrm{CO}_{2}$.

MTT assay. To study cell viability, the colorimetric microculture tetrazolium assay (MTT) was used, as described by Andor et al (23) and Isaia et al (24). Cells were cultured in 96-well plates using a number of $1 \times 10^{4}$ cells/well. After cell attachment, they were treated with five different concentrations (20, 40, 60, 80 and $100 \mathrm{nM}$ ) of RhodOA solubilized in dimethyl sulfoxide (DMSO; Sigma-Aldrich; Merck KGaA) and rhodamine B aqueous solution for 24, 48 and $72 \mathrm{~h}$. The control cells were represented by the cells treated with DMSO, the solvent of OA derivative conjugated with rhodamine $\mathrm{B}$ and water, the solvent used for rhodamine B, respectively.

Following the treatment period, it was added $10 \mu \mathrm{l} /$ well of 3-(4,5-dimethylthiazol-2-yl)-2,5-diphenyltetrazolium bromide (MTT) solution $(5 \mathrm{mg} / \mathrm{ml})$ and after $3 \mathrm{~h}$ of incubation, the MTT precipitates formed were dissolved in $100 \mu \mathrm{l}$ of solubilization buffer provided by the manufacturer. Finally, the reduced MTT was spectrophotometrically measured at $570 \mathrm{~nm}$, using a microplate reader (xMark Microplate Spectrophotometer; Bio-Rad Laboratories, Inc.). All experiments were performed in triplicate.

Immunofluorescence assay. The immunofluorescence assay was performed only on A375-human melanoma cells, as tumor cells, the selection was based on cell viability and cell respiration results; and also, on HaCaT-human keratinocytes as the healthy cells. Cells were cultured in 6-well plates on slides, $1 \times 10^{6}$ cells/well and were stimulated with four different concentrations: 10, 20,30 $\mathrm{nM}$ (the concentrations tested on cell respiration) and $100 \mathrm{nM}$ (highest concentration tested in MTT assay).

The protocol applied for immunofluorescence staining, was based on a protocol described by Gheorgheosu et al (25) and adapted to our laboratory conditions. After $24 \mathrm{~h}$ of stimulation, the cells were fixed with $4 \%$ paraformaldehyde for one hour at room temperature. After fixation, cells were permeabilized using 2\% Triton X-100 solution in phosphate-buffered saline (PBS) for $30 \mathrm{~min}$ at room temperature. To block permeabilization, $30 \%$ FBS solution in $0.01 \%$ Triton X-100 was used for $1 \mathrm{~h}$. Cells were incubated overnight at $4^{\circ} \mathrm{C}$ with primary antibodies Alexa Fluor ${ }^{\circledR} 555$ Phalloidin antibody (Cell Signaling Technology, Inc.) in a 1:20 dilution for visualization of actin 


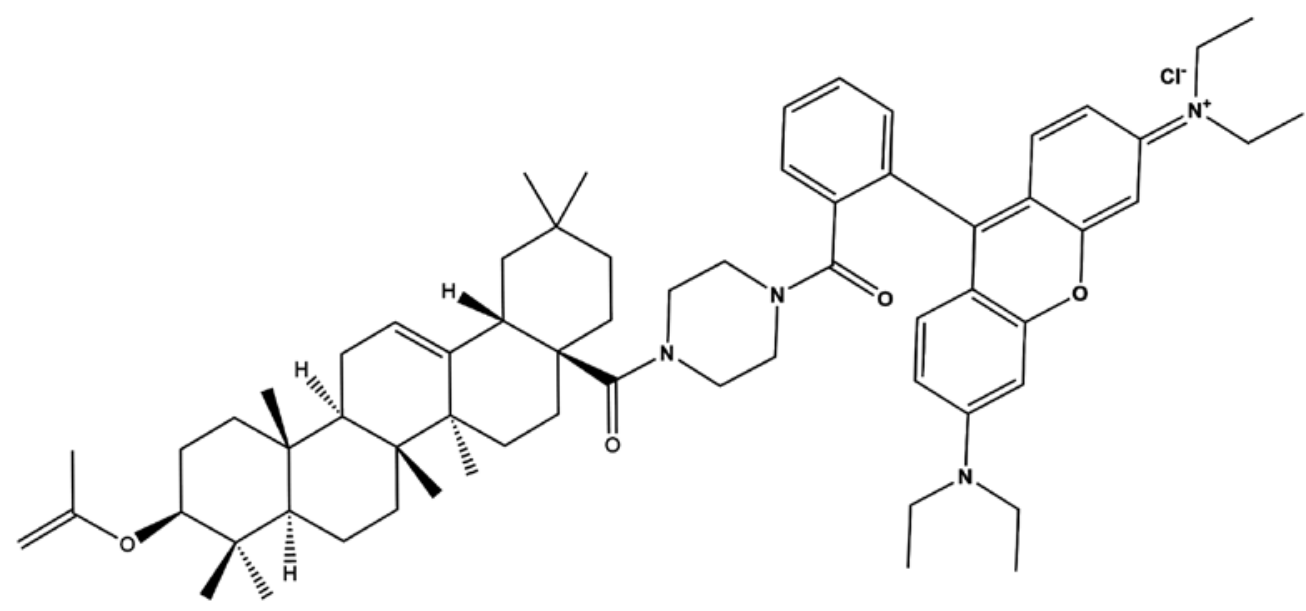

Figure 2. Chemical structure of 9-[2-[[4-(3b-Acetyloxy-olean-12-en-28-oyl)-1-piperazinyl] carbonyl] phenyl]-3,6-bis(diethylamino]-xanthylium chloride (RhodOA).

fibers and Anti-COX IV antibody Mitochondrial marker (ab33985) in a dilution of 1:500. The following day, the primary antibodies were washed with $0.01 \%$ Triton X-100 solution in PBS. The secondary antibody specific for COX IV mitochondrial marker-Donkey anti-goat IgG H\&L (Alexa Fluor ${ }^{\circledR}$ 488-ab150129) was added for $2 \mathrm{~h}$ at room temperature in the dark. The 4',6-diamidino-2-phenylindole (DAPI) staining was used to visualize the nuclei. The images were captured using an Olympus IX73 inverted microscope provided with DP74 camera and analyzed with CellSens V1.15 software (Olympus Corporation) and Image $\mathbf{J}$ software.

Scratch assay. To determine the ability of RhodOA to inhibit the migration of human melanoma A375 cells, scratch assay was performed. The protocol applied was previously described in the literature (26). Briefly, $2 \times 10^{5}$ A375 cells/well were cultured in 12-well plates until it reached $80-90 \%$ confluence. Using a sterile pipette tip, a line was drawn in the middle of the well through the single cell layer. The detached cells were removed by washing with PBS before stimulation. Then, the cells were stimulated with four different concentrations of the derivative (20, 40, 60 and $80 \mathrm{nM})$ and with the solvent used for the preparation of the derivative solutions (DMSO). The cells were immortalized at the time interval of $0 \mathrm{~h}$ and $24 \mathrm{~h}$ and were compared with the unstimulated control cells. Images were taken using the Olympus IX73 inverted microscope provided with DP74 camera (Olympus Corporation), and cell migration analysis was performed using cell Sense Dimension software. In order to calculate the percentage of migration, the formula previously described by Felice et al (27) was applied:

$$
\text { Scratch closure rate }=\left[\left(A_{t_{0}}-A_{t}\right) / A_{t_{0}}\right] \times 100
$$

where, $A_{t_{0}}$, scratch area at time $0 ; A_{t}$, scratch area at $24 \mathrm{~h}$.

High resolution respirometry. Cellular respiratory function was determined by the means of high resolution respirometry studies (Oxygraph-2k Oroboros Ltd.) at $37^{\circ} \mathrm{C}$. To obtain a comprehensive analysis of respiratory control, a substrate-uncoupler-inhibitor titration (SUIT) protocol was followed, designed to allow the measurements of respiratory rates with both separate and convergent Complex I and II (CI+CII) electron input, as described by Petrus et al (28). The cells $\left(1 \times 10^{6} / \mathrm{ml}\right)$ were suspended in a mitochondrial respiration medium (MIRO5: $\mathrm{MgCl}_{2} 3 \mathrm{mM}$, EGTA $0.5 \mathrm{mM}$, taurine $20 \mathrm{mM}, \mathrm{KH}_{2} \mathrm{PO}_{4} 10 \mathrm{mM}$, K-lactobionate $60 \mathrm{mM}$, D-sucrose 110 mM, HEPES 20 mM, BSA 1 g/l, pH 7.1).

In order to allow the passage of soluble molecules between external media and cytosol and to analyze the extended functional oxidative phosphorylation (OXPHOS), plasma membrane was permeabilized by adding a mild detergent: digitonin $\left(35 \mu \mathrm{g} / 1 \times 10^{6}\right.$ cells $)$. The optimum digitonin concentration for selective and complete plasma membrane permeabilization was determined directly in a respirometric protocol, as described by Pesta and Gnaiger (29).

Routine respiratory rates were measured in the presence of cells suspended in mitochondrial respiration media for 10-15 min. The SUIT protocol comprises several steps, as follows: i) addition of digitonin (cells permeabilizer) and the CI substrates (glutamate-G, $10 \mathrm{mM}$ and malate-M, $5 \mathrm{mM}$ ) for State2 (basal respiratory rate) CI assessment; ii) addition of ADP (5 mM) for CI-dependent active respiration (OXPHOS CI) measurement; iii) addition of CII substrate succinate (S, $10 \mathrm{mM}$ ) allowed the convergent electron flow from both $\mathrm{CI}$ and $\mathrm{CII}$ and the measurement of maximal OXPHOS capacity (OXPHOS CI+CII); iv) addition of oligomycin $(1 \mu \mathrm{g} / \mathrm{ml})$ (inhibitor of ATP synthesis) resulted in a non-phosphorylative state and return to basal respiration (State $4 \mathrm{CI}+\mathrm{CII}$ ); v) addition of a decoupling agent, p- (trifluoromethoxy) phenylhydrazone carbonyl cyanide (FCCP) determined the maximum respiratory capacity of the electron transport system (ETS CI+CII); vi) addition of the $\mathrm{CI}$ inhibitor rotenone $(0.5 \mu \mathrm{M})$ was used to measure the ETS capacity, dependent on CII alone (ETS CII); and vii) antimycin A $(1 \mu \mathrm{g} / \mathrm{ml})$, a CIII inhibitor, was added to allow residual oxygen consumption (ROX) to be measured. All respiratory rates were corrected for ROX. After data acquisition, the corresponding flux control ratios (FCRs) that express respiratory control independent of cell size and content in mitochondria was calculated, as follows: i) $\mathrm{P} / \mathrm{E}$ ratio (OXPHOS $\mathrm{CI}+\mathrm{CII} / \mathrm{ETS} \mathrm{CI}+\mathrm{CII}$ ) describes the function of the phosphorylation system; ii) L/E (LEAK/ETS $\mathrm{CI}+\mathrm{CII})$ an indicator of mitochondrial coupling; iii) $\mathrm{R} / \mathrm{E}$ 

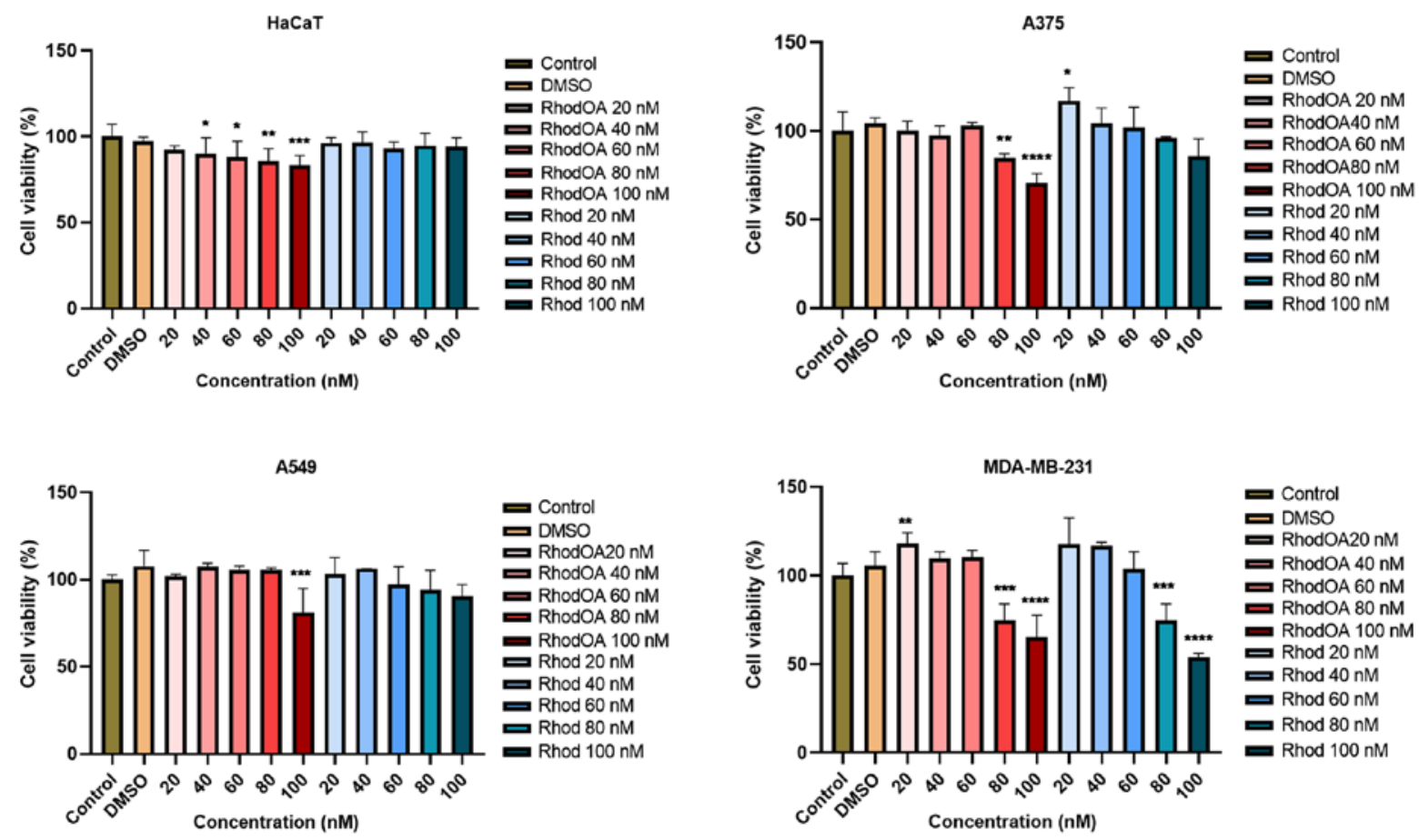

Figure 3. In vitro viability assessment of RhodOA and rhodamine B (20,40,60, 80 and $100 \mathrm{nM})$ after $72 \mathrm{~h}$ in HaCaT human keratinocytes, A375 human melanoma, A549 human lung adenocarcinoma and MDA-MB-231 human breast adenocarcinoma cell lines. The results are expressed as cell viability percentage (\%) normalized to control (DMSO-stimulated) cells. The data represent the mean values \pm SD of three independent experiments performed in triplicate. One-way ANOVA analysis was applied to determine the statistical differences in rapport with DMSO followed by Dunnett's multiple comparisons post-test $\left({ }^{*} \mathrm{P}<0.05,{ }^{* *} \mathrm{P}<0.005,{ }^{* * *} \mathrm{P}<0.001,{ }^{* * * *} \mathrm{P}<0.0001\right)$. DMSO, dimethyl sulfoxide.

(Routine/ETS CI+CII) shows how close the routine respiration is operating to the maximum ETS capacity, thus reflecting the degree of mitochondrial dysfunction; and iv) RCR (OXPHOS CI+CII/STATE2 CI)-indicates the OXPHOS coupling efficiency. The oxygen consumption rates (respiratory rates) were obtained using the software support DatLab 4 (Oroboros Instruments) and statistically analyzed using the GraphPad Prism 5 software (GraphPad Software, Inc.).

Antioxidant activity. The antioxidant capacity of RhodOA and Rhod was measured by their ability to scavenge free radicals using a 2,2-diphenyl-1-picrylhydrazyl (DPPH; Sigma-Aldrich; Merck KGaA) ethanolic solution $0.1 \mathrm{mM}$. DMSO (Sigma-Aldrich; Merck KGaA) and distilled water (Chemical Company SA Iasi) were used as solvents for the dilution of the first (RhodOA) and second (Rhod), respectively. An ethanolic solution (ethanol 80\% (v/v); Chemical Company SA Iasi) of ascorbic acid (Lach-Ner Company) $2 \mathrm{mM}$, was used as standard.

Experiments were carried out using the slightly modified method of Manzocco et al (30). Briefly, $2.5 \mathrm{ml}$ of each sample was mixed with $0.5 \mathrm{ml}$ of DPPH $0.1 \mathrm{mM}$. The absorbance of each sample was recorded continuously at $517 \mathrm{~nm}$ for $10 \mathrm{~min}$, using a T70 UV/VIS spectrophotometer (PG Instruments). The antioxidant activity was calculated using the following formula:

$$
\% \mathrm{AOA}=\left(A_{\text {initial }}-A_{\text {final }}\right) / A_{\text {initial }} \times 100
$$

where, $A_{\text {initial }}$, the absorbance of the DPPH $0.1 \mathrm{mM}$ free radical, without the sample; $A_{\text {final }}$, the absorbance of each sample in mixture with the DPPH $0.1 \mathrm{mM}$ free radical.
The antioxidant activity of each sample was compared to the antioxidant activity of the standard solution (ascorbic acid ethanolic solution $2 \mathrm{mM}$ ). The graphic data was interpreted using Origin 8 Lab software.

The $I C_{50}^{D P P H}$, defined as the concentration of antioxidant compounds from each sample that causes $50 \%$ loss of the DPPH activity was also determined, by using GraphPad Prism 8 software (GraphPad Software, Inc.).

Chorioallantoic membrane (CAM) assay. Fertilized eggs (Gallus gallus domesticus) obtained from a local farm were disinfected with alcohol $70^{\circ}$, dated and incubated in a horizontal position under constant humidity conditions and a temperature of $37^{\circ} \mathrm{C}$. On the $3 \mathrm{rd}$ day of incubation, $7 \mathrm{ml}$ of albumen was extracted to allow the CAM to detach from the eggshell so that the blood vessels could be easily observed. On the fourth day of incubation, a window was cut and covered with adhesive tape, and the eggs were incubated until the day of the experiment.

The study was conducted starting with the 7th day of incubation. The effect of the RhodOA on angiogenesis was recorded for 5 days. During this time, the blood vessels have an increased rate of development similar to the tumor angiogenesis process (31). Five concentrations of RhodOA (20, 40, 60, 80 and $100 \mathrm{nM}$ ) and the 0.5\% DMSO solvent were tested in triplicates. A volume of $10 \mu \mathrm{l}$ was applied inside a $5 \mathrm{~mm}$ diameter ring placed previously on the CAM surface. The microscopic evaluation was done daily by means of a Discovery 8 Stereomicroscope (Zeiss), while images were captured for analysis using Axio CAM 105 color (Zeiss) and Image J software. 


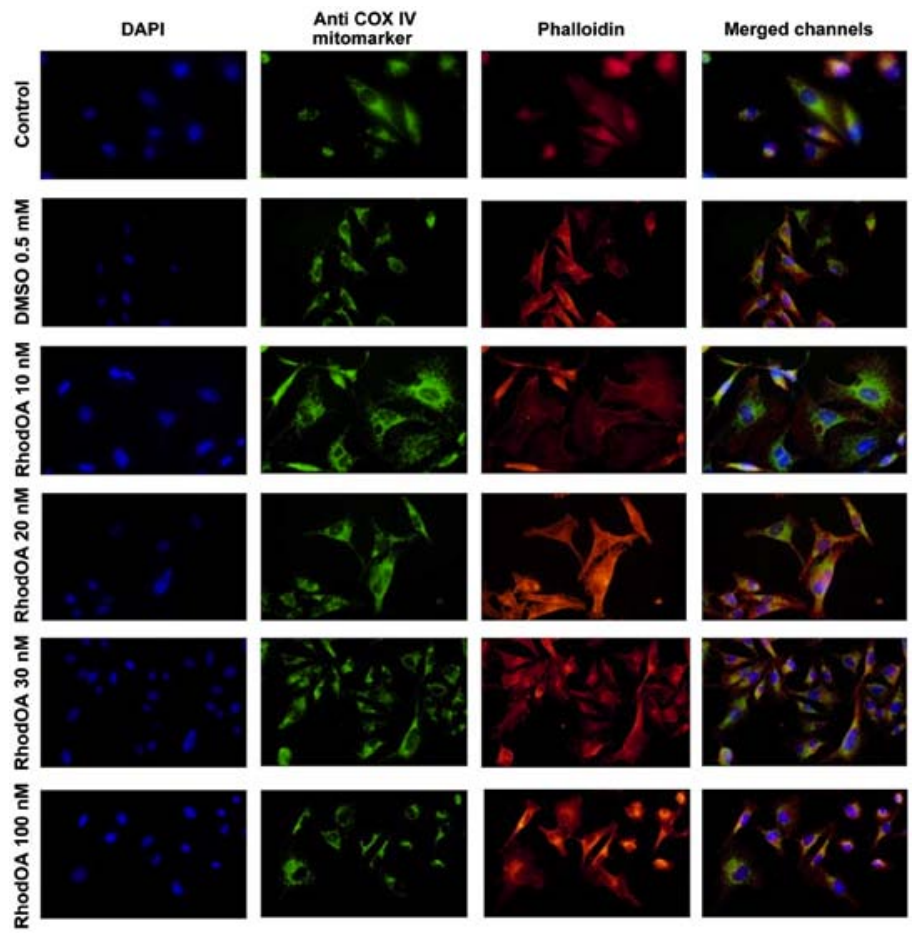

Figure 4. Effect of RhodOA (10, 20, 30 and $100 \mathrm{nM})$ and DMSO $(0.5 \mathrm{mM})$ after $24 \mathrm{~h}$ of stimulation on the A375 cells on nuclei. DAPI staining (blue), F-actin fibers-Phalloidin (red) and COX IV mitochondrial marker (green). DMSO, dimethyl sulfoxide.

Hen egg test-CAM (HET-CAM) assay. To evaluate the biocompatibility and toxicity of RhodOA, the Hen egg test (HET-CAM) was assessed. The eggs were prepared as described above in the CAM method. Five eggs were used for each test solution. For each solution, a volume of $500 \mu 1$ was tested. The changes observed in CAM were evaluated using a stereomicroscope (Discovery 8 Stereomicroscope; Zeiss) and the images were performed (Axio CAM 105 color; Zeiss) before and after a $5 \mathrm{~min}$ application. All images were processed using ImageJ v $1.50 \mathrm{e}$ software (U.S. National Institutes of Health).

Water was used as negative control, and $1 \%$ sodium dodecylsulfate (SDS) in $\mathrm{H}_{2} \mathrm{O}$ was used as positive control. The test samples were diluted in DMSO at a concentration of 80 and $100 \mathrm{nM}$.

The effects on blood vessels, hemorrhage $(\mathrm{H})$, vessel lysis (L) and coagulation and extra vascular (C) were monitored for $5 \mathrm{~min}$. The analytical method used to determine the irritant effect was to calculate the irritation score (IS) using the formula (32):

$$
I S=5 \times \frac{301-H}{300}+7 \times \frac{301-L}{300}+9 \times \frac{301-C}{300}
$$

where, IS was between 0 and 21.

Determination of anti-irritative potential. The eggs were prepared as indicated above. The method was adapted to our laboratory conditions (33). To determine the anti-irritant effect of RhodOA, the two previously tested concentrations ( 80 and $100 \mathrm{nM}$ ) were applied to the CAM in a volume of $600 \mu \mathrm{l}$. The eggs were introduced into the incubator for $3 \mathrm{~h}$ to allow the solution to be absorbed into the membrane. After $3 \mathrm{~h}$, the eggs were treated with $300 \mu \mathrm{l}$ $0.5 \%$ SDS in $\mathrm{H}_{2} \mathrm{O}$. The membrane was observed for $5 \mathrm{~min}$ and the vascular effects of lysis, stasis and hemorrhage were monitored.

\section{Results}

RhodOA induces a dose-dependent decrease of tumor cell viability. In order to determine the impact of the tested compound on cells viability, five different concentrations (20, 40, 60, 80 and $100 \mathrm{nM}$ ) were tested in lung cancer (A549), breast cancer (MDA-MB-231) and human melanoma (A375) cell lines as compared to a healthy human keratinocyte cell line (HaCaT). Cell viability was determined by MTT assay at 3 time intervals: 24,48 and $72 \mathrm{~h}$, respectively. At 24 and $48 \mathrm{~h}$ no significant effect was observed in the tumor cell lines; however, at $72 \mathrm{~h}$ a dose-dependent decrease in cell viability was noted in all the tumor lines, the most affected being the human melanoma cell line A375 (Fig. 3). In contrast, the $\mathrm{HaCaT}$ cells viability was slightly decreased at $20 \mathrm{nM}$ concentration (up to $92 \%$ ), while the highest concentration of the derivative, $100 \mathrm{nM}$, decreased viability to $83 \%$. In parallel, 5 different concentrations of rhodamine B (20, 40, 60, 80 and $100 \mathrm{nM}$ ) were tested; a slight dose-dependent decrease of cell viability was recorded but compared to the RhodOA derivative the decrease was not statistically significant.

RhodOA induces reorganization of A375 cytoskeleton and nuclei condensation. Changes in the nucleus, actin fibers and mitochondria morphological aspects were assessed by fluorescence microscopy in human melanoma A375 cells and human keratinocytes HaCaT.

An immunofluorescence assay was performed to determine the RhodOA mechanism of action responsible for cytotoxicity 


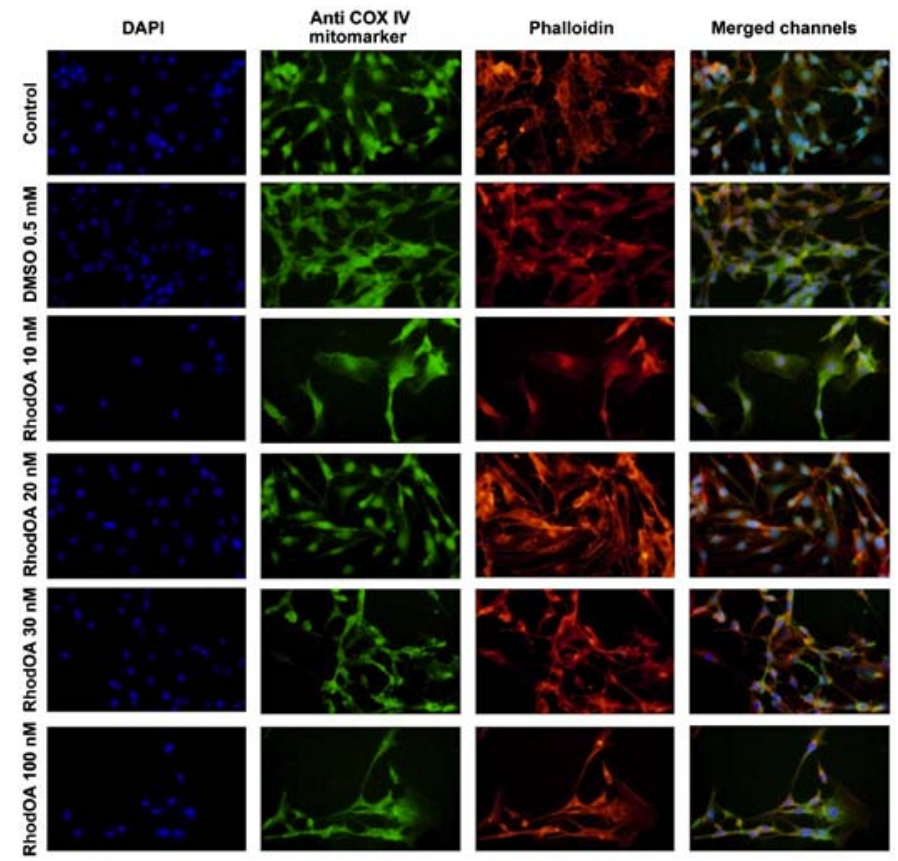

Figure 5. Effect of RhodOA (10, 20, 30 and $100 \mathrm{nM})$ and DMSO $(0.5 \mathrm{mM})$ after $24 \mathrm{~h}$ of stimulation on the HaCaT cells on nuclei. DAPI staining (blue), F-actin fibers-Phalloidin (red) and COX IV mitochondrial marker (green). DMSO, dimethyl sulfoxide.

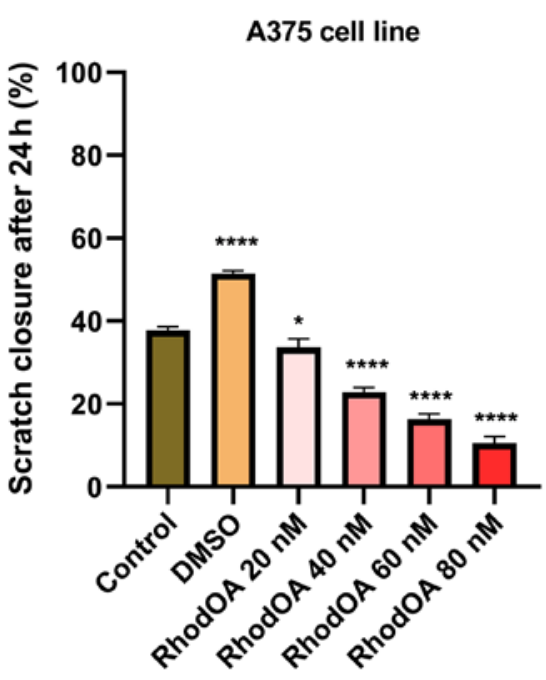

Figure 6. Scratch closure rate of A375 following RhodOA treatment (20, 40,60 and $80 \mathrm{nM}$ ). The graph shows the percentage of scratch closure after $24 \mathrm{~h}$ compared to the initial surface. The comparison between-groups was performed using One-way ANOVA test followed by Dunnett's post-test $\left({ }^{*} \mathrm{P}<0.05 ;{ }^{* * * *} \mathrm{P}<0.001\right.$ vs. control cells).

in human melanoma cells. By DAPI staining assay, it was observed that RhodOA induced a condensation of the nuclei in the case of the A375 cells, the most visible effect being recorded at a concentration of $100 \mathrm{nM}$ (Fig. 4). In the case of the human keratinocytes (Fig. 5), the condensation of the nuclei was not so visible. Therefore, it can be concluded that RhodOA has a selective proapoptotic effect on the human melanoma cells.

The morphology and organization of actin fibers were evaluated in human melanoma cells and human keratinocytes after their treatment with different concentrations of RhodOA. In the case of human melanoma cells (Fig. 4), in the control cells, a network of branched actin fibers that runs along the cells was observed. Following treatment with RhodOA, a condensation of actin fibers was noticed, the strongest effect being recorded at a concentration of $100 \mathrm{nM}$. For human keratinocytes (Fig. 5) no significant changes in the structure and organization of actin fibers were noted.

By using the Anti-COX IV antibody Mitochondrial marker, we were able to gather information on the localization of mitochondria in A375 and HaCaT cells (Fig. 4) with and without RhodOA pretreatment. In A375 cells an increase in mitochondria concentration near the nucleus upon treatment with increasing concentrations of RhodOA was noted. In the $\mathrm{HaCaT}$ cells no modifications in terms of mitochondria distribution were detected (Fig. 5).

RhodOA inhibits A375 cell migration in a dose-dependent manner. In order to determine the effect of the OA derivative on cellular migration, the scratch assay was performed. Human melanoma cells were stimulated with four different concentrations of the derivative $(20,40,60$ and $80 \mathrm{nM})$, and were compared to unstimulated control cells and solvent (DMSO)-stimulated cells.

Stimulation of the A375 cells with RhodOA produced a dose-dependent anti-migratory effect (Fig. 6). At the lowest concentration of $20 \mathrm{nM}$, a closure of $35.6 \%$ was recorded, similar to that of the control group. At the concentration of 40 and $60 \mathrm{nM}$, the closure rate was 22.97 and $16.10 \%$, respectively. At the highest tested concentration $(80 \mathrm{nM})$, the derivative strongly inhibited cell migration, presenting the lowest closure rate $(10.76 \%)$. In addition, after $24 \mathrm{~h}$ of stimulation, a slight modification in cell morphology was noted and some cells detached from the plate, which suggests that RhodOA has a cytotoxic effect against the melanoma cells (Fig. 7).

High-resolution respirometry studies. To study the effect on cellular respiration, three increasing concentrations of 

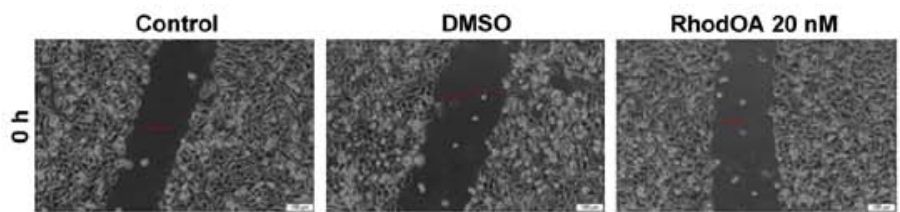

RhodOA 40 nM

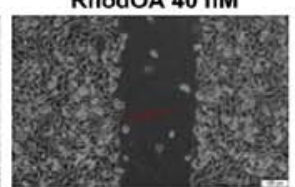

RhodOA $60 \mathrm{nM}$

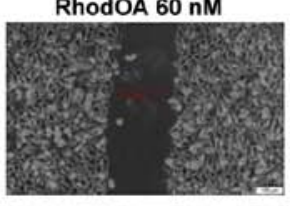

RhodOA $80 \mathrm{nM}$
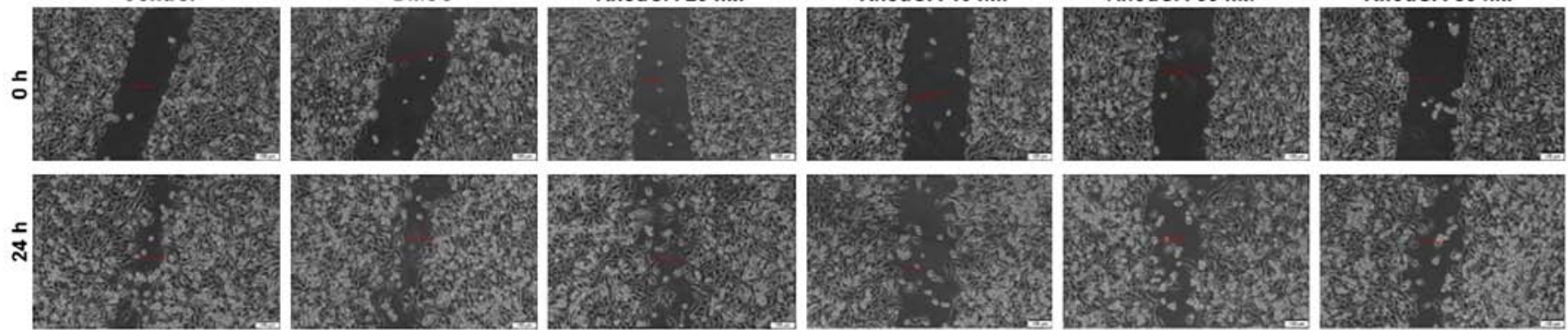

Figure 7. Representative images of the A375 scratch assay. Images were captured at 0 and 24 h after stimulation with RhodOA versus control cells
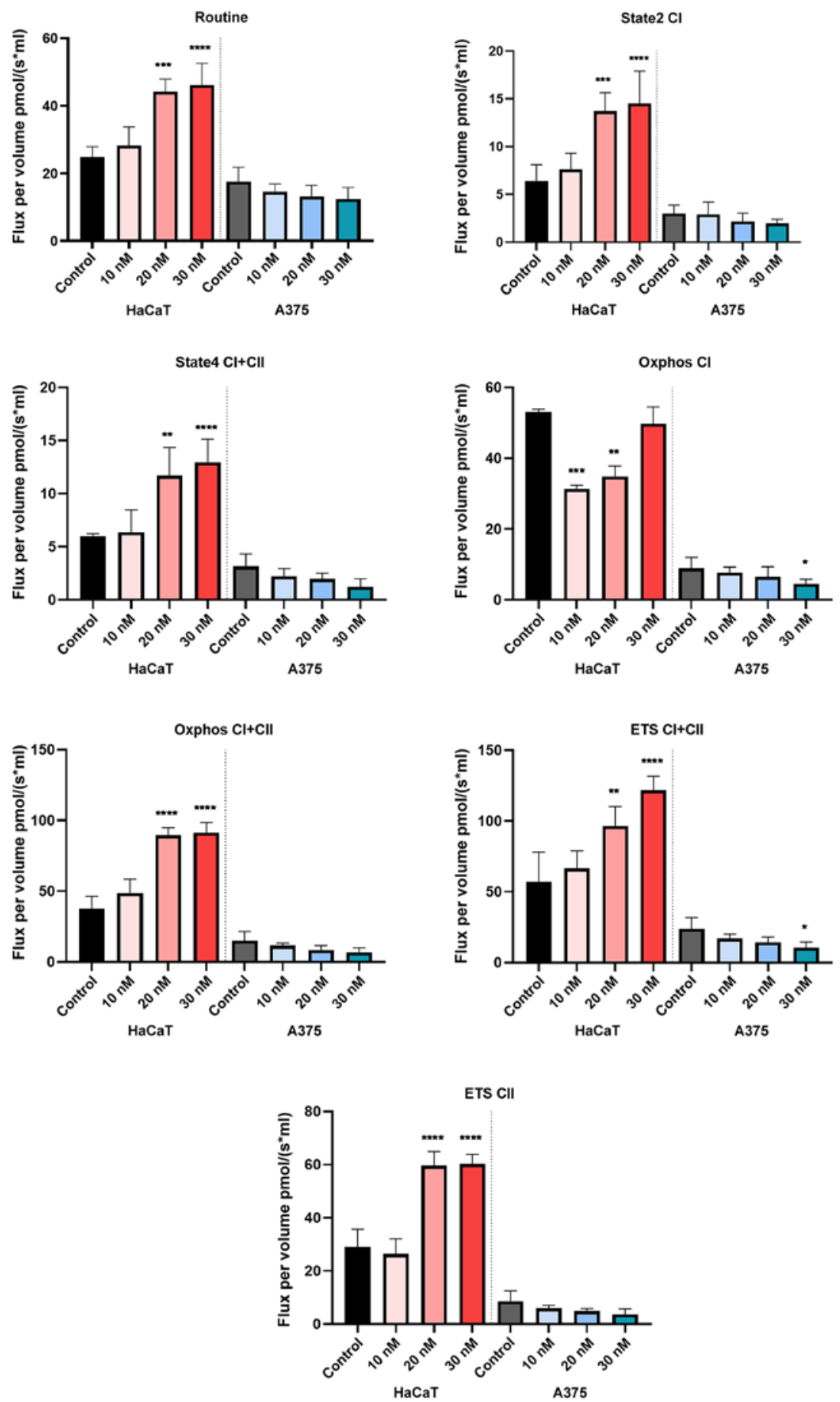

Figure 8. Effect of acute treatment with RhodOA (10, 20 and $30 \mathrm{nM})$ on cellular respiration in HaCaT human keratinocytes and A375 human melanoma cell lines. Data are presented as mean values \pm SD results from three independent experiments. The comparison between the groups was performed using the one-way ANOVA test, followed the by Dunnett's post-test. ${ }^{*} \mathrm{P}<0.05,{ }^{* *} \mathrm{P}<0.005,{ }^{* * *} \mathrm{P}<0.001,{ }^{* * * *} \mathrm{P}<0.0001$. 
Table I. Effect of acute treatment with RhodOA (10, 20 and $30 \mathrm{nM})$ on P/E, L/E, R/E and RCR in HaCaT-human keratinocytes and A375-human melanoma cell lines.

\begin{tabular}{|c|c|c|c|c|c|c|c|c|}
\hline & \multicolumn{2}{|c|}{$\mathrm{P} / \mathrm{E}$} & \multicolumn{2}{|c|}{$\mathrm{L} / \mathrm{E}$} & \multicolumn{2}{|c|}{$\mathrm{R} / \mathrm{E}$} & \multicolumn{2}{|c|}{ RCR } \\
\hline & $\mathrm{HaCaT}$ & A375 & $\mathrm{HaCaT}$ & A375 & $\mathrm{HaCaT}$ & A375 & $\mathrm{HaCaT}$ & A375 \\
\hline Control & 0.787418 & 0.521129 & 0.133967 & 0.141969 & 0.463907 & 0.729738 & 6.213332 & 5.058102 \\
\hline RhodOA $10 \mathrm{nM}$ & 0.722780 & 0.683028 & 0.125734 & 0.164756 & 0.428187 & 0.841086 & $8.509565^{\mathrm{a}}$ & 6.490921 \\
\hline RhodOA $20 \mathrm{nM}$ & 1.010007 & 0.642803 & 0.131158 & 0.138359 & 0.466503 & 1.003413 & $4.770558^{\mathrm{a}}$ & 4.87191 \\
\hline RhodOA $30 \mathrm{nM}$ & 0.751809 & 0.637909 & 0.126915 & 0.217103 & 0.377931 & $1.218005^{\mathrm{a}}$ & 6.422751 & 6.102949 \\
\hline
\end{tabular}

Data are presented as mean values \pm SD results from three independent experiments. Comparison between the groups was performed using the one-way ANOVA test, followed the by Dunnett's post-test $\left({ }^{\mathrm{a}} \mathrm{P}<0.05\right)$.

Table II. The inhibition percentage of ascorbic acid $2 \mathrm{mM}$, RhodOA and Rhod (20, 40, 60 and $80 \mathrm{nM}$ ), when reacting with $0.1 \mathrm{mM}$ DPPH, after $10 \mathrm{~min}$.

\begin{tabular}{lrrrrrrr}
\hline \multicolumn{2}{c}{ Ascorbic acid in ethanol 80\% } & & \multicolumn{2}{c}{ RhodOA solution in DMSO } & & \multicolumn{2}{c}{ Rhod solution in distilled water } \\
\cline { 1 - 2 } Concentration (mM) & \% inhibition & & Concentration (nM) & \% inhibition & & Concentration (nM) & \% inhibition \\
\hline 2 & $94.16 \pm 0.0589$ & & 20 & $83.08 \pm 0.0089$ & & 20 & $83.70 \pm 0.0086$ \\
1 & $91.60 \pm 0.0075$ & & 40 & $82.27 \pm 0.0093$ & & 40 & $83.70 \pm 0.0086$ \\
0.6 & $49.51 \pm 0.0451$ & & 60 & $83.34 \pm 0.0623$ & & 60 & $84.68 \pm 0.0571$ \\
0.3 & $31.72 \pm 0.0610$ & & 80 & $84.61 \pm 0.0081$ & & 80 & $83.60 \pm 0.0086$ \\
0.1 & $9.20 \pm 0.0811$ & & 100 & $84.31 \pm 0.0083$ & & 100 & $84.71 \pm 0.0080$ \\
\hline
\end{tabular}

The results are expressed as average $\pm \operatorname{SD}(n=3)$.

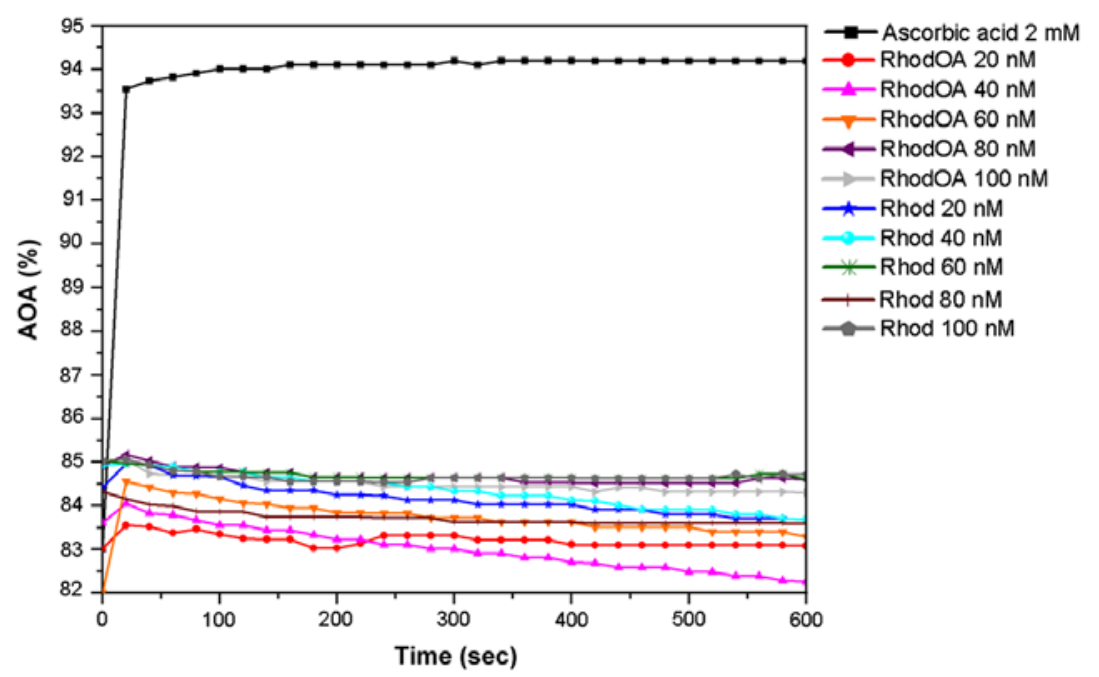

Figure 9. Antioxidant activity of RhodOA and Rhod at different concentrations (20,40, 60, 80 and $100 \mathrm{nM})$ vs. standard-ascorbic acid ethanolic solution $(2 \mathrm{mM})$, using $0.1 \mathrm{mM}$ ethanolic DPPH solution, in time.

RhodOA (10, 20 and $30 \mathrm{nM})$ were tested in HaCaT and A375 cells.

The compound produced a dose-dependent increase in all respiratory rates in the HaCaT cells, whereas, in the case of A375 cells, a dose-dependent decrease of all respiratory rates, $\mathrm{P} / \mathrm{E}$ and RCR and an increase of FCRs: L/E and R/E were recorded. The decrease of respiratory rates: State2 CI and State $4 \mathrm{CI}+\mathrm{CII}$ suggests that the tested compound decreases oxygen consumption when the phosphorylation system is in an inactive state due to a decrease in proton leak/slip across the inner mitochondrial membrane. In addition, our results show that RhodOA inhibits active respiration and decreases 
Table III. IS for SDS, DMSO and RhodOA 80 and $100 \mathrm{nM}$ and the occurrence time of hemorrhage (tH), lysis (tL) and coagulation $(\mathrm{tC})$.

\begin{tabular}{lcccc}
\hline & SDS 1\% & DMSO 0.5\% & RhodOA 80 nM & RhodOA 100 nM \\
\hline IS & 19.17 & 1.15 & 1.87 & 2.07 \\
tH & $18 \mathrm{sec}$ & 300 & 300 & 180 \\
tL & $23 \mathrm{sec}$ & 300 & 300 & 300 \\
tC & $35 \mathrm{sec}$ & 264 & 240 & 300 \\
\hline
\end{tabular}

IS, Irritation score; SDS, sodium dodecylsulfate; DMSO, dimethyl sulfoxide.
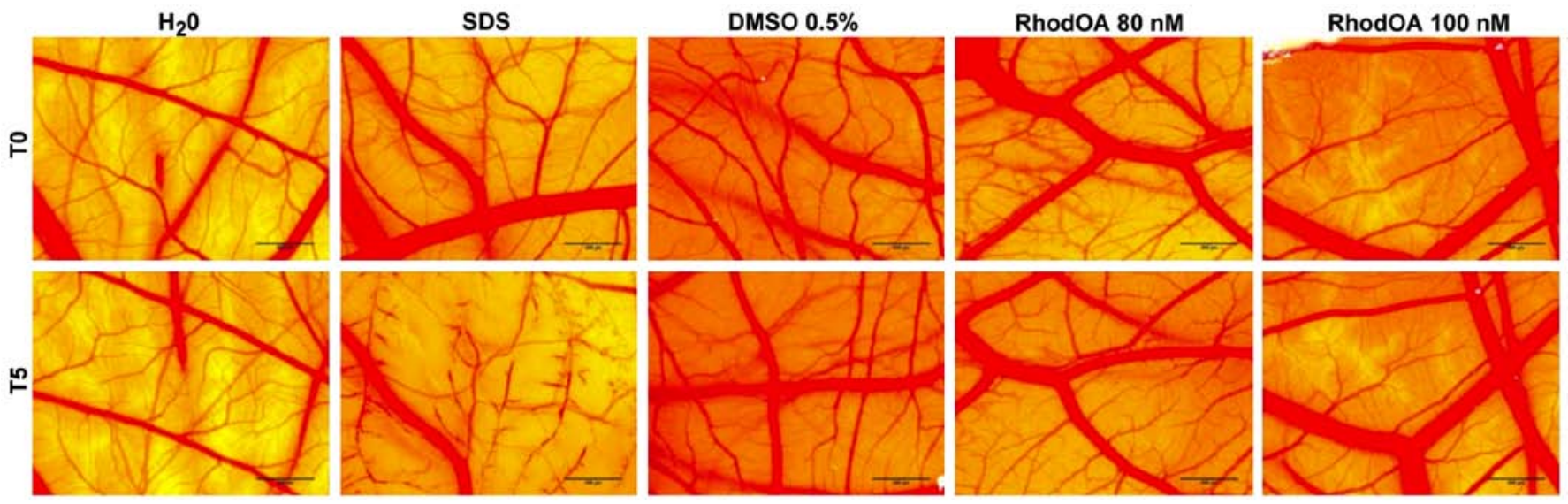

Figure 10. Analysis of the irritant potential of RhodOA by the HET-CAM method. Stereomicroscopic images of CAMs inoculated with negative control. $\mathrm{H}_{2} \mathrm{O}$, positive control, SLS, solvent used to solubilize RhodOA-DMSO 0.05\% and test compound, RhodOA 80 and $100 \mathrm{nM}$. DMSO, dimethyl sulfoxide; CAM, chorioallantoic membrane.

the maximal respiratory capacity of the electron transfer system, by lowering the respiratory rates of OXPHOS CI and OXPHOS CI+CII simultaneously with the decrease of ETS CI+CII and ETS CII. As displayed in Fig. 8, in A375 cells, the routine respiration (i.e., when cell respiration is controlled by the physiological aerobic ATP demand) is decreased in a dose-dependent manner when RhodOA was applied (Table I).

Antioxidant activity. The antioxidant activity (AOA) was assessed by means of the DPPH method. Two sets of samples [RhodOA and rhodamine B (Rhod)] of different concentrations $(20,40,60,80$ and $100 \mathrm{nM})$ were tested.

As presented in Fig. 9, when the $0.1 \mathrm{mM}$ ethanolic DPPH solution was used, both RhodOA and Rhod showed antioxidant activity compared to ascorbic acid. More precisely, the antioxidant activity of RhodOA and Rhod samples was above $80 \%$, being slightly increased at the beginning of the reaction and gently decreasing towards the end of the reaction. This pattern was similar for almost all samples, except RhodOA $20 \mathrm{nM}$ and RhodOA $60 \mathrm{nM}$, in which antioxidant activity was slightly higher at the end of the reaction compared to the initial moment. The maximum antioxidant activity was reached in the case of RhodOA 100 and $60 \mathrm{nM}(85.03 \%)$ and Rhod $100 \mathrm{nM}(84.71 \%)$ samples; the antioxidant activity of ascorbic acid was $94.19 \%$.

The RhodOA and Rhod samples quenche the DPPH free radical after the first $50 \mathrm{sec}$, subsequently the reaction reaches equilibrium, except RhodOA $40 \mathrm{nM}$, Rhod 20 and $40 \mathrm{nM}$, in which antioxidant activity decreases visibly.

As shown in Fig. 9, the antioxidant activity of the analyzed samples is not concentration-dependent, at the initial moment nor after $10 \mathrm{~min}$ of reaction with DPPH free radical, its values oscillating over time (Table II).

The $I C_{50}^{D P P H}$ values for ascorbic acid $2 \mathrm{mM}\left(\mathrm{IC}_{50}=63.65 \mathrm{nM}\right)$, RhodOA $\left(\mathrm{IC}_{50}=60.44 \mathrm{nM}\right)$ and $\operatorname{Rhod}\left(\mathrm{IC}_{50}=52.82 \mathrm{nM}\right)$ were also calculated when reacting with $0.1 \mathrm{mM}$ DPPH ethanolic solution, using equation (2) described above.

RhodOA has no toxic effect in ovo. The toxic potential of the RhodOA was tested in ovo using chicken CAM as the biological medium; the protocol allowed the assessment of its potential irritant effect following topical application. The effect induced by the compound along with the effects induced by positive (SDS) and negative controls (water), respectively, were recorded as photographs before and after 5 min of contact with the CAM. Hemorrhage, coagulation and lysis of blood vessels were detected only in SDS treated CAMs.

The highest IS was present only in the SDS-treated CAM, whereas the negative control and the test compound caused no irritant effect. The application of $500 \mu \mathrm{l}$ SDS induces massive damage to blood vessels, causing micro-hemorrhage, coagulation and vascular lysis occurring on an extended membrane area. The death of specimens treated with SDS was noted after 
Table IV. Anti-irritant effect of RhodOA 80 and $100 \mathrm{nM}$ and solvent DMSO 0.5\% after CAM irritation with SDS 0.5\%.

\begin{tabular}{lcccc}
\hline & SDS $0.5 \%$ & DMSO $0.5 \%+$ SDS & RhodOA $80 \mathrm{nM}+$ SDS & RhodOA 100 nM + SDS \\
\hline $\mathrm{IS}$ & 18.68 & 18.43 & 17.03 & 17 \\
$\mathrm{tH}$ & $55 \mathrm{sec}$ & $24 \mathrm{sec}$ & $90 \mathrm{sec}$ & $90 \mathrm{sec}$ \\
$\mathrm{tL}$ & $44 \mathrm{sec}$ & $90 \mathrm{sec}$ & $70 \mathrm{sec}$ & $80 \mathrm{sec}$ \\
$\mathrm{tC}$ & $14 \mathrm{sec}$ & $4 \mathrm{sec}$ & $30 \mathrm{sec}$ & $23 \mathrm{sec}$ \\
$\mathrm{H}_{\mathrm{AI}}$ & & 0.43 & 1.63 & 1.63 \\
$\mathrm{~L}_{\mathrm{AI}}$ & & 2.04 & 1.59 & 1.81 \\
$\mathrm{C}_{\mathrm{AI}}$ & & 0.28 & 2.14 & 1.64
\end{tabular}

DMSO, dimethyl sulfoxide; SDS, sodium dodecylsulfate; CAM, chorioallantoic membrane.

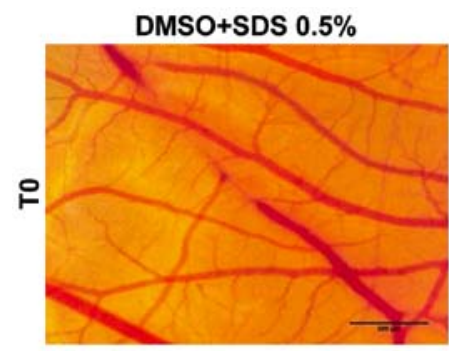

RhodOA $80 \mathrm{nM}+$ SDS $0.5 \%$
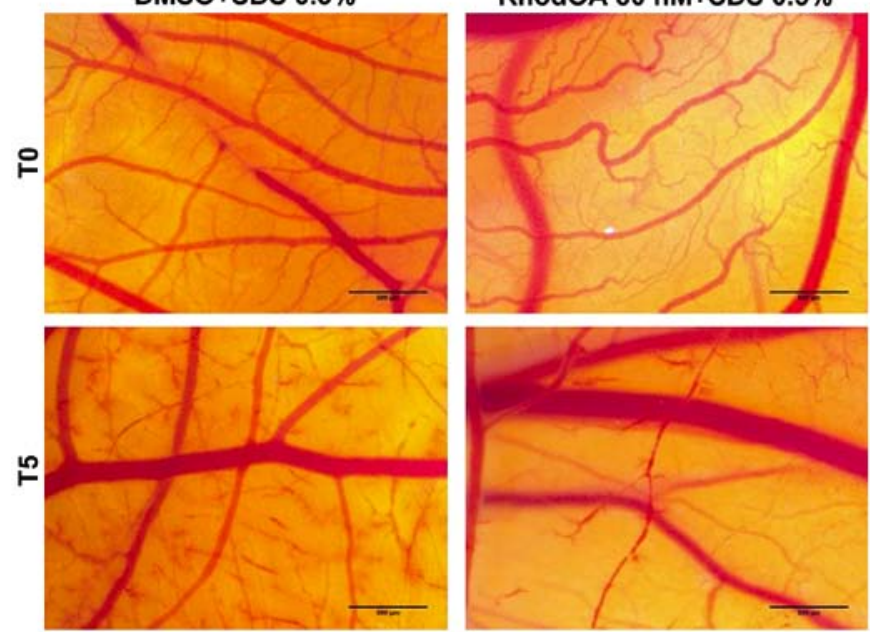
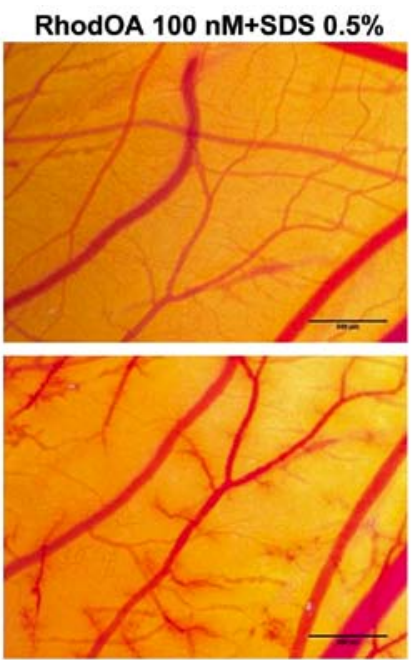

Figure 11. Stereomicroscopic images of CAM after irritation with SDS and treatment with RhodOA 80 and $100 \mathrm{nM}$ and DMSO 0.5\%. CAM, chorioallantoic membrane; SDS, sodium dodecylsulfate; DMSO, dimethyl sulfoxide.

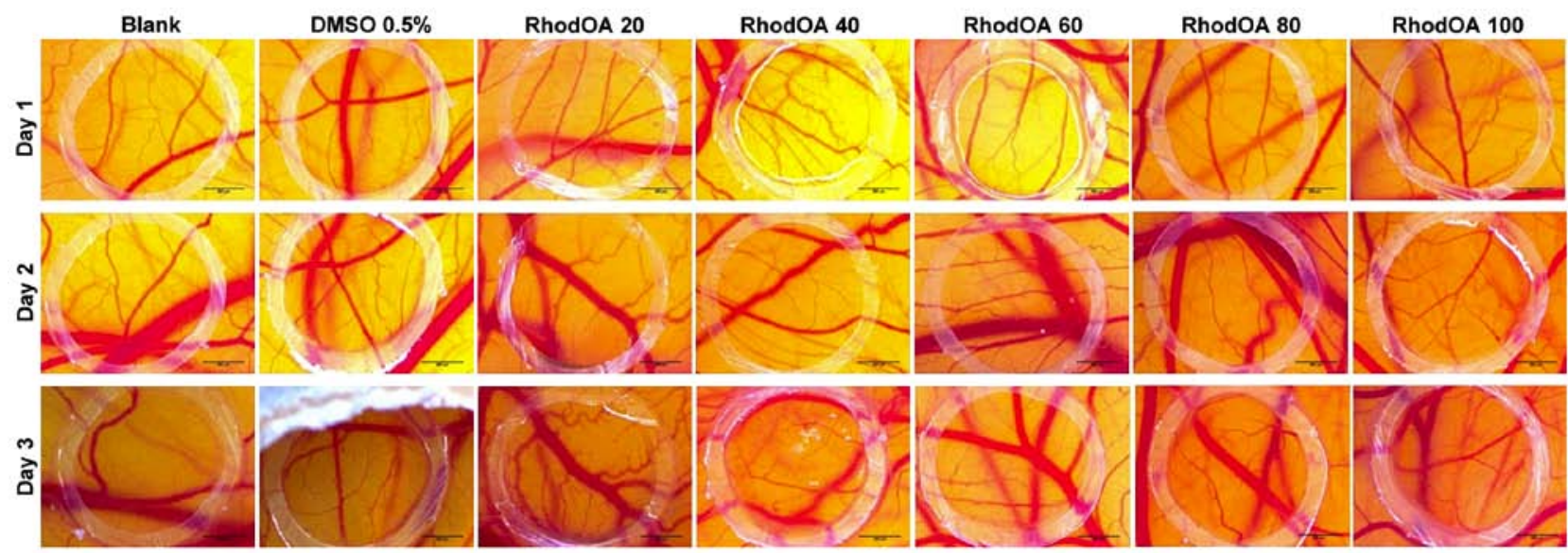

Figure 12. Effect of RhodOA (20,40, 60, 80 and $100 \mathrm{nM})$ and 0.05\% DMSO on CAM assay on normal angiogenesis after 3 days of treatment. DMSO, dimethyl sulfoxide; CAM, chorioallantoic membrane.

$60 \mathrm{~min}$. For non-irritative samples, a viability of over $24 \mathrm{~h}$ was recorded.

Both tested concentrations of RhodOA, 80 and $100 \mathrm{nM}$ were non-irritative to the vascular plexus of the CAM (Fig. 10; Table III).
RhodOA exhibits a moderate anti-irritant potential. In order to determine the potential anti-irritant effect of the tested compound, we proceeded with a preventive application of the test solutions and DMSO as control, prior to the SDS irritative intervention. The same parameters as for the 
HET-CAM assay were registered ( $\mathrm{H}, \mathrm{L}$ and $\mathrm{S}$ time in seconds), both with and without pre-treatment of test samples. Thus, the following parameters for the anti-irritant effect were calculated: $H_{A I}=H / H_{S D S}$ : hemorrhage time after pretreatment with RhodOA and SDS addition 0.5\%/hemorrhage time without pretreatment with RhodOA; $L_{A I}=L / L_{S D S}$ : vascular lysis time after pretreatment with RhodOA and SDS addition $0.5 \% / v a s c u l a r$ lysis time without pretreatment with RhodOA; $C_{A I}=C / C_{S D S}$ : vascular coagulation time after pretreatment with RhodOA and SDS addition 0.5\%/vascular coagulation time without pretreatment with RhodOA.

Table IV presents the irritability score (IS) after treatment with RhodOA $80 \mathrm{nM}\left(\mathrm{IS}_{\text {RhodOA80 }}\right)$ and $100 \mathrm{nM}\left(\mathrm{IS}_{\text {RhodOA100 }}\right), \mathrm{H}$, $\mathrm{L}$ and $\mathrm{C}$ onset times before treatment; $\mathrm{H}_{\mathrm{RhodOA}}, \mathrm{L}_{\mathrm{RhodOA}}$ and $\mathrm{C}_{\mathrm{RhodOA}}$ after pretreatment and administration of $0.5 \% \mathrm{SDS}$ and $\mathrm{H}_{\mathrm{AI}}, \mathrm{L}_{\mathrm{AI}}$ and $\mathrm{C}_{\mathrm{AI}}$ parameters.

The lack of anti-irritative effect can clearly be seen for DMSO, while RhodOA induces a reduction of the IS value of SDS with no pre-treatment. Both concentrations of RhodOA induce a similar moderate anti-irritative effect (Fig. 11).

RhodOA presents a dose-dependent anti-angiogenic effect. The anti-angiogenic effect of the OA-rhodamine B derivative was tested in vivo using the CAM assay. Chicken embryo specimens showed good viability and survival rate, allowing compound testing up to approximately ED11. After 3 days of treatment, a change in the vascular network was observed. Fig. 12 shows a decrease in vascular density, with numerous areas with a low number of capillaries inside the ring. This decrease in the number of newly formed vessels is directly proportional to the concentration tested, significant results were obtained in the case of the highest tested concentration $(100 \mathrm{nM})$.

\section{Discussion}

Old strategies, which aimed to treat cancer just by the induction of cell death, are no longer relevant. New therapeutic approaches that also target the tumor microenvironment treatment, immune/inflammatory response modulation, stopping angiogenesis and resistance of cancer cell death by using highly selective compounds with a specific action and with reduced systemic toxic effects, represent the focus of the current trends in cancer research. Therefore, an increasing number of preclinical and epidemiological studies support the beneficial effect of phytochemicals in cancer $(34,35)$. Due to their selectivity against cancer cells and the plethora of biological activities (anticancer, anti-inflammatory, anti-angiogenic, antioxidant, antibacterial, antiviral and antifungal), the use of triterpenes have emerged as a multifaceted potential alternative in cancer prevention and treatment (36). Among triterpenes, the antiproliferative effect of OA has been described in various types of cancer, such as: breast cancer (4), lung cancer (3), liver cancer (37), skin cancer $(38,39)$, gastric cancer $(40)$, pancreatic cancer (41), prostate cancer (42) and in leukemia (43).

In order to increase its therapeutic potential in cancer treatment, numerous derivatizations of OA have been performed. A study by Wiemann et al (44) evaluated the cytotoxic potential of hydroxiaminated derivatives of $\mathrm{OA}$ and revealed that the obtained derivatives exhibit higher cytotoxic effect on certain tumor cell lines (breast cancer, MCF-7, lung cancer, A549) and a lower cytotoxic activity against healthy cell lines (nonmalignant mouse fibroblasts, NIH 3T3). Another study demonstrated that by introducing a double bond at $\mathrm{C}$ ring, a derivative with superior antitumor effect is obtained by increasing ROS production, caspase-9 activity and inducing mitochondrial mediated apoptosis in MCF-7, breast cancer cell line (14). Heller et al (15) showed that 3-O-acetyl-OA derived carboxamides also have a superior antitumor effect compared to OA when applied on several human tumor cell lines, by inducing cell cycle arrest and cell death via autophagy or apoptosis. In line with the previous stated findings, Xie et al (45), reported the synthesis of a rhodamine-B-docetaxel conjugate, in order to obtain improved mitochondrial delivery and increased cytotoxicity; results showed the specific delivery of the compound to mitochondria and improved antitumor effect.

Similarly, pentacyclic triterpenoic acid rhodamine B esters or piperazine-spacered rhodamine B amides were shown to be more cytotoxic on various cancer cell lines compared with their parent compound $(12,46)$. The present work aimed to further investigate oleanolic acid-rhodamine B (RhodOA) mechanism of action by a series of in vitro and in ovo biological studies. Thus, the effect of RhodOA on cellular viability was first assessed in three tumor cell lines: lung cancer (A549), breast cancer (MDA-MB-231) and human melanoma (A375) cell lines and in a healthy human keratinocyte cell line (HaCaT). We found that after $72 \mathrm{~h}$ exposure, RhodOA significantly decreased cell viability, in a dose-dependent manner, in all three different types of cancer cell lines (the most significant effect was observed in A375 cells, cell line selected for further investigations), whereas healthy human keratinocyte cells were not affected. Moreover, RhodOA induced a dose-dependent anti-migratory effect in A375 cell line (Fig. 6). As suggested by the obtained data, RhodOA presents selective antitumor activity as well as reduced toxicity on healthy cells.

One of the hallmarks of cancer is the immense ability of tumor cells to evade apoptosis. A large number of literature studies revealed that defects in the apoptotic pathways have an important role in carcinogenesis and thus, treatment strategies that target apoptosis can be successfully used in cancer therapy $(47,48)$. The morphological changes associated with apoptosis include: formation of apoptotic bodies, nuclear condensation, DNA fragmentation, cell shrinkage and membrane alterations (49). Several recent studies indicated that OA can induce the above-mentioned morphological changes in HepG2-human hepatocellular carcinoma cell line (50), in HeLa-human cervical cancer cell line (51) and in various human astrocytoma cell lines (52). Similar morphological changes of apoptosis were reported when OA derivatives were used against SMMC-7721 human hepatocellular carcinoma cell line (53), K562 human leukemia cell line (54) and B16-F10 melanoma cell line, respectively (55). Moreover, another cytotoxic triterpenoid, piperazine, of rhodamine B derivatives were reported to accumulate in mitochondria and to trigger apoptosis in A2780 ovarian carcinoma cells (46). Our results are in line with all these findings, showing that RhodOA produced a condensation of the nuclei, a hallmark of apoptosis, with the highest effect being detected when the highest concentration was used (100 nM, Fig. 4), visible only 
in the case of A375 cells and not in the HaCaT cells; therefore, a high degree of selectivity can be assumed. However, a deeper analysis is required to evaluate all the morphological changes associated with apoptosis and to conclude on the pro-apoptotic effect of the new OA-rhodamine B derivative.

The tumor invasion and metastasizing capacity depends on the cancer cell ability to move, and hence by the actin content. Our findings regarding the evaluation of actin fiber organization, in A375 human melanoma cells, revealed that treatment with RhodOA causes significant changes in the $\mathrm{F}$-actin pattern, increasing the condensation of F-actin, the strongest effect being observed at $100 \mathrm{nM}$, while untreated A375 human melanoma cells presented a normal morphology and actin spread (Fig. 4). For HaCaT human keratinocytes, no significant changes in the structure and organization of actin fibers were observed (Fig. 5). These results suggest that the RhodOA influences the cytoskeleton arrangement of human melanoma cells; similar results were obtained in astrocytoma cell lines treated with OA (52).

As reviewed by Kim et al (56), due to the essential role that mitochondria play in energy metabolism, signaling pathways and cell death, they are implicitly involved in tumor initiation, growth, metastasis and even in drug resistance. Numerous studies have tried to identify the antitumor mechanisms of action of OA. Zhu et al (50) found that OA induces apoptosis in liver cancer cells by affecting mitochondria in a dose-dependent manner (50). Another study reported that OA induced apoptosis in human hepatocellular carcinoma (HuH7) cell lines through mitochondria-mediated pathway (57). Similarly, when tested on A549 lung cancer cells, OA produces ultrastructural alterations of the mitochondria, increases ROS production and causes mitochondria autophagy, a process known as mitophagy (58).

In the present study, we evaluated the effects of a new RhodOA conjugate on mitochondrial respiration in healthy human keratinocytes ( $\mathrm{HaCaT})$ and on human melanoma tumor cells (A375). When applied to the A375 cells, RhodOA decreased routine respiration in a dose-dependent manner (Fig. 8). Mitochondrial respiration and phosphorylation in the routine state are controlled by energy demand and turnover and the degree of mitochondrial coupling (29). The results also revealed a dose-dependent inhibition of the active respiration (OXPHOS) in the A375 cells as well as an increase of the active respiration in HaCaT cells (Fig. 8). However, mitochondrial uncoupling/toxicological dyscoupling can contribute to flux control in the OXPHOS state. In order to see if the decrease of OXPHOS observed in the A375 cells treated with RhodOA is a result of RhodOA acting as a mitochondrial uncoupler (i.e., by increasing the proton leak across the inner mitochondrial membrane, thus uncoupling the link between ADP phosphorylation in ATP and substrate oxidation) the values of State $4 \mathrm{CI}+\mathrm{CII}$ were analyzed (Fig. 8). As presented by Terada (59) uncoupling agents increase State4 respiratory rate. Interestingly, our results showed a decrease of the State4 CI+CII respiratory rate, suggesting that RhodOA decreases proton leak/slip across the inner mitochondrial membrane and does not act as mitochondrial uncoupler. Hence, we can assume that the detected decrease of OXPHOS is a direct consequence of low ADP phosphorylation in ATP. Taken together these results suggests that treatment with RhodOA impaired mitochondrial function and the capacity to produce sufficient levels of ATP in
A375 melanoma cells without inducing toxicity in the healthy human keratinocyte cells HaCaT. As previously demonstrated, ATP loss in cancer cells leads to energy depletion, cellular stress, and ultimately may induce cell death through different pathways $(60,61)$. Contrary to the traditional belief that cancer cells present mitochondrial damage and consecutive metabolic inability, current studies have demonstrated that mitochondrial respiration is not impaired in many cancers (62). By calculating FCRs (Table I), we obtained valuable information regarding mitochondrial integrity, efficiency and more importantly, how the tested compound influenced mitochondrial functions. In A375 cells treated with RhodOA the results revealed a decrease of RCR and P/E parallel with an increase of L/E and R/E vs. control, thus suggesting that RhodOA decreases the capacity of the phosphorylation system. In addition, the L/E and R/E increase observed in the A375 cell tests (Table I) suggests an increased cellular ATP demand or the existence of a limitation in the mitochondrial respiratory capacity produced by defects in substrate oxidation or in ETS complexes after treatment with RhodOA (29). By correlating the high antitumor effect with the relevant intervention on mitochondrial respiration, we can presume that the new OA-rhodamine B derivative exhibits a 'MITOCAN' behavior.

As presented in a recent review by Yang etal (63), ROS role in cancer is like a double-edged sword, being a tumor-suppressing or a tumor-promoting agent, with vast evidence that supports both cases. However, this dichotomy of ROS in cancer cells depends on the stage of cancer progression; in early stages moderate ROS induce tumor growth and metastasis, whilst in late stages, with tumor progression, increasing ROS levels can lead to apoptosis, cell death and senescence (64). In the case of human melanoma cells, studies concluded that ROS play an important role in increasing the metastasis potential, by inducing DNA mutations and cell proliferation and by activating molecules involved in metastasis, such as: urokinase plasminogen receptor activator, interleukin-8, epidermal growth factor receptor, and vascular endothelial growth factor (65). In lung cancer, increasing ROS produce changes at the DNA level and in the structure of lipids, carbohydrates and proteins, thus leading to proliferation and metastasis of cancer cells (66). A study performed on MDA-MB-231 breast cancer cell lines concluded that ROS stimulate angiogenesis and favor the metastasis process (67). In terms of the effect phytochemicals exhibit in cancer, a study revealed that OA had an anti-proliferative effect while increasing the oxidative stress in various breast cancer cell lines, thus being a pro-oxidant agent (68). Controversially, on HCT 116 colon cancer cell line, OA exhibited anti-proliferative and antioxidant activity (69). The free radical scavenging activity of OA, analyzed through the same DPPH method used in the current work, showed that OA has a significant free radical inhibitory activity compared to the standard antioxidant ascorbic acid $\left(\mathrm{IC}_{50}=61.5 \mu \mathrm{g} / \mathrm{ml}\right.$; $132 \mu \mathrm{M})(69)$. This is in line with our findings, according to which RhodOA maintains the free radical scavenging activity exhibited by OA; moreover, RhodOA has a stronger antioxidant effect at $100 \mathrm{nM}$, comparable to that of the ascorbic acid control solution (RhodOA IC $50=60.44 \mathrm{nM}$ ).

Tumor development and progression represents a cumulative molecular and phenotypic modification of epithelial cells (70). Angiogenesis is one of the processes that underlies 
tumor development and progression. New blood vessel development is stimulated when tumor cells require increasing amounts of nutrients and oxygen due to a high and rapid proliferation rate $(71,72)$. Therefore, inhibition of angiogenesis can result in tumor growth inhibition. Regarding the effect of OA on angiogenesis, an important effect in inhibiting the formation of blood vessels has been observed in the case of Sk-Mel-2 melanoma cells (73). The anti-angiogenic effect of OA has been previously tested using the CAM method and it was proven to have the potential to reduce vascular density and reduce capillary count in a concentration of $30 \mu \mathrm{M}$ (73).

In this study, the effects of a novel OA-rhodamine B derivative were evaluated on angiogenesis and a decrease was detected in the vascular density and a lower number of capillaries after 3 days of treatment (Fig. 12). The best recorded results in terms of the number of newly formed vessels were recorded for the highest tested concentration (100 nM), a lower dose compared to that previously used for the parent compound (74). The literature contains data regarding optimized anti-angiogenic effect of certain OA derivatives; CDDO-Me (methyl 2-cyano-3,12-dioxoolean-1,9-dien-28-oate) and CDDO-Imm (2-cyano-3,12-dioxoolean-1,9-dien-28-oic imidazolide), exhibited increased anti-angiogenic effect, by preventing endothelial cell tubulogenesis, at low doses in the Matrigel sponge assay, being also able to inhibit tumor growth in an immortalized Kaposi's sarcoma cell line (74).

In conclusion, this study brings valuable evidence that an oleanolic acid-rhodamine B derivative, RhodOA, display antitumor properties against lung cancer, breast cancer and human melanoma cell lines without inducing toxic effects on human healthy keratinocytes. Moreover, when tested in human melanoma cells, RhodOA was able to produce a condensation of the nuclei and of F-actin. Despite the limitations of this study, the above-mentioned results suggest that RhodOA is involved in the apoptotic process of cancer cells as well as in suppressing tumor invasion and metastasis. A significant improvement of the anti-angiogenic potential compared to the parent compound OA was observed for the novel rhodamine B derivative. Furthermore, the novel formulation RhodOA showed an increased free radical scavenging activity compared to OA alone. In melanoma cells, RhodOA impaired mitochondrial function and the capacity to produce sufficient levels of ATP, whilst the mitochondrial function of healthy human keratinocytes was left intact. The observed antitumor effect can be correlated with the intervention that RhodOA has on mitochondrial respiration, therefore the new OA-rhodamine $\mathrm{B}$ derivative can be classified as a 'MITOCAN'. Even though further studies are still needed to unravel its full mechanism of action, this study sheds light on the immense therapeutic anticancer potential of this novel OA derivative.

\section{Acknowledgments}

Not applicable.

\section{Funding}

This study was supported by an internal grant at 'Victor Babes' University of Medicine and Pharmacy (grant no. 2DOC/1299/31.01.2020.

\section{Availability of data and materials}

Not applicable.

\section{Authors' contributions}

VD, CD, CS: designed and directed the project; CD, AT: provided critical feedback and helped shape the research, analysis and manuscript; IM, AM, DC, VLD: contributed to the interpretation of the results; IM, S,A, AM: carried out the experiments; IM, DAS, AM, CS, DC: wrote the manuscript with input from all authors. All the authors discussed the results and contributed to the final manuscript.

\section{Ethics approval and consent to participate}

Not applicable.

\section{Patient consent for publication}

Not applicable.

\section{Competing interests}

DAS is the Editor-in-Chief for the journal, but had no personal involvement in the reviewing process, or any influence in terms of adjudicating on the final decision, for this article. The other authors declare that they have no competing interests.

\section{References}

1. Ferlay J, Colombet M, Soerjomataram I, Dyba T, Randi G, Bettio M, Gavin A, Visser O and Bray F: Cancer incidence and mortality patterns in Europe: Estimates for 40 countries and 25 major cancers in 2018. Eur J Cancer 103: 356-387, 2018.

2. Kroschinsky F, Stölzel F, von Bonin S, Beutel G, Kochanek M, Kiehl $\mathrm{M}$ and Schellongowski P; Intensive Care in Hematological and Oncological Patients (iCHOP) Collaborative Group: New drugs, new toxicities: Severe side effects of modern targeted and immunotherapy of cancer and their management. Crit Care 21: 89, 2017.

3. Zhao X, Liu M and Li D: Oleanolic acid suppresses the proliferation of lung carcinoma cells by miR-122/Cyclin G1/MEF2D axis. Mol Cell Biochem 400: 1-7, 2015.

4. Wu J, Yang C, Guo C, Li X, Yang N, Zhao L, Hang H, Liu S, Chu P, Sun Z, et al: SZC015, a synthetic oleanolic acid derivative, induces both apoptosis and autophagy in MCF-7 breast cancer cells. Chem Biol Interact 244: 94-104, 2016.

5. Li L, Wei L, Shen A, Chu J, Lin J and Peng J: Oleanolic acid modulates multiple intracellular targets to inhibit colorectal cancer growth. Int J Oncol 47: 2247-2254, 2015.

6. Oprean C, Ivan A, Bojin F, Cristea M, Soica C, Drăghia L, Caunii A, Paunescu V and Tatu C: Selective in vitro anti-melanoma activity of ursolic and oleanolic acids. Toxicol Mech Methods 28: 148-156, 2018.

7. Wang X, Bai H, Zhang X, Liu J, Cao P, Liao N, Zhang W, Wang Z and Hai C: Inhibitory effect of oleanolic acid on hepatocellular carcinoma via ERK-p53-mediated cell cycle arrest and mitochondrial-dependent apoptosis. Carcinogenesis 34: 1323-1330, 2013.

8. Kim GJ, Jo HJ, Lee KJ, Choi JW and An JH: Oleanolic acid induces p53-dependent apoptosis via the ERK/JNK/AKT pathway in cancer cell lines in prostatic cancer xenografts in mice. Oncotarget 9: 26370-26386, 2018.

9. Mu DW, Guo HQ, Zhou GB, Li JY and Su B: Oleanolic acid suppresses the proliferation of human bladder cancer by Akt/mTOR/S6K and ERK1/2 signaling. Int J Clin Exp Pathol 8: 13864-13870, 2015. 
10. Senthilkumar PK, Kandhavelu M and Reetha D: Antioxidant properties of the oleanolic acid isolated from Cassia auriculata (Linn). J Pharm Res Clin Pract 4: 30-36, 2014.

11. Sohn KH, Lee HY, Chung HY, Young HS, Yi SY and Kim KW: Anti-angiogenic activity of triterpene acids. Cancer Lett 94: 213-218, 1995.

12. Sommerwerk S, Heller L, Kerzig C, Kramell AE and Csuk R: Rhodamine $\mathrm{B}$ conjugates of triterpenoic acids are cytotoxic mitocans even at nanomolar concentrations. Eur J Med Chem 127: 1-9, 2017.

13. Salvador JAR, Leal AS, Valdeira AS, Gonçalves BMF, Alho DPS, Figueiredo SAC, Silvestre SM and Mendes VIS: Oleananeursane-, and quinone methide friedelane-type triterpenoid derivatives: Recent advances in cancer treatment. Eur J Med Chem 142: 95-130, 2017.

14. Pattnaik B, Lakshma Nayak V, Ramakrishna S and Venkata Mallavadhani U: Synthesis of ring-C modified oleanolic acid derivatives and their cytotoxic evaluation. Bioorg Chem 68: 152-158, 2016.

15. Heller L, Knorrscheidt A, Flemming F, Wiemann J, Sommerwerk S, Pavel IZ, Al-Harrasi A and Csuk R: Synthesis and proapoptotic activity of oleanolic acid derived amides. Bioorg Chem 68: 137-151,2016.

16. Yan X, Zhou Y and Liu S: Optical imaging of tumors with copper-labeled rhodamine derivatives by targeting mitochondria. Theranostics 2: 988-998, 2012

17. Lampidis TJ, Hasin Y, Weiss MJ and Chen LB: Selective killing of carcinoma cells 'in vitro' by lipophilic-cationic compounds: A cellular basis. Biomed Pharmacother 39: 220-226, 1985.

18. Johnson LV, Walsh ML and Chen LB: Localization of mitochondria in living cells with rhodamine 123. Proc Natl Acad Sci USA 77: 990-994, 1980.

19. Vyas S, Zaganjor E and Haigis MC: Mitochondria and Cancer. Cell 166: 555-566, 2016.

20. Porporato PE, Filigheddu N, Pedro JMB, Kroemer G and Galluzzi L: Mitochondrial metabolism and cancer. Cell Res 28 265-280, 2018.

21. Weinberg SE and Chandel NS: Targeting mitochondria metabolism for cancer therapy. Nat Chem Biol 11: 9-15, 2015.

22. Yang Y, Karakhanova S, Hartwig W, D'Haese JG, Philippov PP, Werner J and Bazhin AV: Mitochondria and mitochondrial ROS in cancer: novel targets for anticancer therapy. J Cell Physiol 231: 2570-2581, 2016

23. Andor B, Tischer AA (Tucuina), Berceanu-Vaduva D, Lazureanu V, Cheveresan A and Poenaru M: Antimicrobial activity and cytotoxic effect on gingival cells of silver nanoparticles obtained by biosynthesis. Rev Chim 70: 781-783, 2019.

24. Isaia AI (Oarcea), Ienascu IMC, Andrica FM, Georgescu D, Bratosin D and Pinzaru IA: Preliminary in vitro evaluation of seven different plant extracts on A375, B164A5 and HaCat cell lines. Rev Chim 68: 1633-1636, 2016.

25. Gheorgheosu D, Jung M, Ören B, Schmid T, Dehelean C, Muntean D and Brüne B: Betulinic acid suppresses NGAL-induced epithelial-to-mesenchymal transition in melanoma. Biol Chem 394: 773-781, 2013.

26. Ghițu A, Schwiebs A, Radeke HH, Avram S, Zupko I, Bor A, Pavel IZ, Dehelean CA, Oprean C, Bojin F, et al: A comprehensive assessment of apigenin as an antiproliferative, proapoptotic, antiangiogenic and immunomodulatory phytocompound. Nutrients 11: 858, 2019.

27. Felice F, Zambito Y, Belardinelli E, Fabiano A, Santoni T and Di Stefano R: Effect of different chitosan derivatives on in vitro scratch wound assay: A comparative study. Int J Bio Macromol 76: 236-241, 2015.

28. Petrus A, Ratiu C, Noveanu L, Lighezan R, Rosca M, Muntean DO: Assessment of mitochondrial respiration in human platelets. Revista De Chimie 68: 768-771, 2017.

29. Pesta D and Gnaiger E: High-resolution respirometry: OXPHOS protocols for human cells and permeabilized fibers from small biopsies of human muscle. Methods Mol Biol 810: 25-58, 2012.

30. Manzocco L, Anese M and Nicoli MC: Antioxidant properties of tea extracts as affected by processing. LWT - Food Sci Technol 31: 694-698, 1998.

31. Nowak-sliwinska P, Segura T and Iruela-Arispe ML: The chicken chorioallantoic membrane model in biology, medicine and bioengineering. Angiogenesis 17: 779-804, 2015.

32. Batista-Duharte A, Jorge Murillo G, Pérez UM, Tur EN, Portuondo DF, Martínez BT, Téllez-Martínez D, Betancourt JE and Pérez O: The hen's egg test on chorioallantoic membrane: An alternative assay for the assessment of the irritating effect of vaccine adjuvants. Int J Toxicol 35: 627-633, 2016.
33. Moacă EA, Farcas C, Coricovac D, Avram S, Mihali CV, Drâghici GA, Loghin F, Păcurariu C and Dehelean C: Oleic acid double coated $\mathrm{Fe}_{3} \mathrm{O}_{4}$ nanoparticles as anti-melanoma compounds with a complex mechanism of activity - in vitro and in ovo assessment. J Biomed Nanotechnol 15: 893-909, 2019.

34. Orlikova B, Legrand N, Panning J, Dicato M and Diederich M: Anti-inflammatory and anticancer drugs from nature. Cancer Treat Res 159: 123-143, 2014.

35. Tuorkey MJ: Cancer therapy with phytochemicals: Present and future perspectives. Biomed Environ Sci 28: 808-819, 2015

36. Chudzik M, Korzonek-Szlacheta I and Król W: Triterpenes as potentially cytotoxic compounds. Molecules 20: 1610-1625, 2015.

37. Shi Y, Song Q, Hu D, Zhuang X, Yu S and Teng D: Oleanolic acid induced autophagic cell death in hepatocellular carcinoma cells via PI3K/Akt/mTOR and ROS-dependent pathway. Korean J Physiol Pharmacol 20: 237-243, 2016.

38. Lúcio KA, Rocha G da G, Monção-Ribeiro LC, Fernandes J, Takiya CM and Gattass CR: Oleanolic acid initiates apoptosis in non-small cell lung cancer cell lines and reduces metastasis of a B16F10 melanoma model in vivo. PLoS One 6: e28596, 2011.

39. Tokuda H, Ohigashi H, Koshimizu K and Ito Y: Inhibitory effects of ursolic and oleanolic acid on skin tumor promotion by 12-O-tetradecanoylphorbol-13-acetate. Cancer Lett 33: 279-285, 1986.

40. Gao L, Xu Z, Wang Y, Sun B, Song Z, Yang B, Liu X, Lin Y, Peng J, Han G, et al: Anticancer effect of SZC017, a novel derivative of oleanolic acid, on human gastric cancer cells. Oncol Rep 35: 1101-1108, 2016.

41. Wei J, Liu M, Liu H, Wang H, Wang F, Zhang Y, Han L and Lin X: Oleanolic acid arrests cell cycle and induces apoptosis via ROS-mediated mitochondrial depolarization and lysosomal membrane permeabilization in human pancreatic cancer cells. J Appl Toxicol 33: 756-765, 2013.

42. Li X, Song Y, Zhang P, Zhu H, Chen L, Xiao Y and Xing Y: Oleanolic acid inhibits cell survival and proliferation of prostate cancer cells in vitro and in vivo through the PI3K/Akt pathway. Tumour Biol 37: 7599-7613, 2016.

43. Zhang P, Li H, Chen D, Ni J, Kang Y and Wang S: Oleanolic acid induces apoptosis in human leukemia cells through caspase activation and poly(ADP-ribose) polymerase cleavage. Acta Biochim Biophys Sin (Shanghai) 39: 803-809, 2007.

44. Wiemann J, Heller L and Csuk R: Targeting cancer cells with oleanolic and ursolic acid derived hydroxamates. Bioorg Med Chem Lett 26: 907-909, 2016.

45. Xie C, Chang J, Hao X-D, Yu J-M, Liu H-R and Sun X: Mitochondrial-targeted prodrug cancer therapy using a rhodamine B labeled fluorinated docetaxel. Eur J Pharm Biopharm 85 (3 Pt A): 541-549, 2013.

46. Wolfram RK, Heller L and Csuk R: Targeting mitochondria: Esters of rhodamine $\mathrm{B}$ with triterpenoids are mitocanic triggers of apoptosis. Eur J Med Chem 152: 21-30, 2018.

47. Wong RS: Apoptosis in cancer: From pathogenesis to treatment. J Exp Clin Cancer Res 30: 87, 2011.

48. Ferreira CG, Epping M, Kruyt FAE and Giaccone G: Apoptosis: Target of cancer therapy. Clin cancer Res 8: 2024-2034, 2002.

49. Balba A and Catoi C: Tumor cell morphology. In: Comparative Oncology. The Publishing House of the Romanian Academy, Bucharest, 2007.

50. Zhu YY, Huang HY and Wu YL: Anticancer and apoptotic activities of oleanolic acid are mediated through cell cycle arrest and disruption of mitochondrial membrane potential in HepG2 human hepatocellular carcinoma cells. Mol Med Rep 12: 5012-5018, 2015

51. Song X, Liu CC, Hong YR and Zhu XC: Anticancer activity of novel oleanolic acid methyl ester derivative in HeLa cervical cancer cells is mediated through apoptosis induction and reactive oxygen species production. Bangladesh J Pharmacol 10: 896, 2015.

52. Martín R, Carvalho-Tavares J, Ibeas E, Hernández M, Ruiz-Gutierrez V and Nieto ML: Acidic triterpenes compromise growth and survival of astrocytoma cell lines by regulating reactive oxygen species accumulation. Cancer Res 67: 3741-3751, 2007.

53. Fan X, Wang P, Sun Y, Jiang J, Du H, Wang Z, Duan Z, Lei H and $\mathrm{Li} \mathrm{H}$ : Induction of apoptosis by an oleanolic acid derivative in SMMC-7721 human hepatocellular carcinoma cells is associated with mitochondrial dysfunction. Oncol Lett 15: 2821-2828, 2017.

54. Pan S, Hu J, Zheng T, Liu X, Ju Y and Xu C: Oleanolic acid derivatives induce apoptosis in human leukemia K562 cell involved in inhibition of both Akt1 translocation and pAkt1 expression. Cytotechnology 67: 821-829, 2015. 
55. Reyes-Zurita FJ, Medina-O'Donnell M, Ferrer-Martin RM, Rufino-Palomares EE, Martin-Fonseca S, Rivas F, Martínez A, García-Granados A, Pérez-Jiménez A, García-Salguero L, et al: The oleanolic acid derivative, 3-O-succinyl-28- $O$-benzyl oleanolate, induces apoptosis in B16-F10 melanoma cells via the mitochondrial apoptotic pathway. RSC Advances 6: 93590-93601, 2016.

56. Kim HK, Noh YH, Nilius B, Ko KS, Rhee BD, Kim N and Han J: Current and upcoming mitochondrial targets for cancer therapy. Semin Cancer Biol 47: 154-167, 2017.

57. Shyu MH, Kao TC and Yen GC: Oleanolic acid and ursolic acid induce apoptosis in $\mathrm{HuH} 7$ human hepatocellular carcinoma cells through a mitochondrial-dependent pathway and downregulation of XIAP. J Agric Food Chem 58: 6110-6118, 2010.

58. Castrejón-Jiménez NS, Leyva-Paredes K, Baltierra-Uribe SL, Castillo-Cruz J, Campillo-Navarro M, Hernández-Pérez AD, Luna-Angulo AB, Chacón-Salinas R, Coral-Vázquez RM, Estrada-García I, et al: Ursolic and oleanolic acids induce mitophagy in A549 human lung cancer cells. Molecules 24: $3444,2019$.

59. Terada H: Uncouplers of oxidative phosphorylation. Environ Health Perspect 87: 213-218, 1990.

60. Iglesias-Figueroa BF, Siqueiros-Cendón TS, Gutierrez DA, Aguilera RJ, Espinoza-Sánchez EA, Arévalo-Gallegos S, Varela-Ramirez A and Rascón-Cruz Q: Recombinant human lactoferrin induces apoptosis, disruption of F-actin structure and cell cycle arrest with selective cytotoxicity on human triple negative breast cancer cells. Apoptosis 24: 562-577, 2019.

61. Izyumov DS, Avetisyan AV, Pletjushkina OY, Sakharov DV, Wirtz KW, Chernyak BV and Skulachev VP: 'Wages of fear' Transient threefold decrease in intracellular ATP level imposes apoptosis. Biochim Biophys Acta 1658: 141-147, 2004.

62. Potter M, Newport E and Morten KJ: The Warburg effect: 80 years on. Biochem Soc Trans 44: 1499-1505, 2016.

63. Yang H, Villani RM, Wang H, Simpson MJ, Roberts MS, Tang M and Liang $\mathrm{X}$ : The role of cellular reactive oxygen species in cancer chemotherapy. J Exp Clin Cancer Res 37: 266, 2018.

64. Aggarwal V, Tuli HS, Varol A, Thakral F, Yerer MB, Sak K, Varol M, Jain A, Khan MA and Sethi G: Role of reactive oxygen species in cancer progression: molecular mechanisms and recent advancements. Biomolecules 9: 9, 2019.
65. Mishra R, Patel H, Yuan L and Garrett JT: Role of reactive oxygen species target metastatic melanoma. Cancer Res Front 4: 101-130, 2018

66. Azad N, Rojanasakul Y and Vallyathan V: Inflammation and Lung cancer: roles of reactive oxygen/nitrogen species. J Toxicol Environ Health B Crit Rev 11: 1-15, 2008.

67. Liu Y, Cui Y, Shi M,Zhang Q, Wang Q and Chen X: Deferoxamine promotes MDA-MB-231 cell migration and invasion through increased ROS-dependent HIF-1 $\alpha$ accumulation. Cell Physiol Biochem 33: 1036-1046, 2014.

68. Sánchez-Quesada C, López-Biedma A and Gaforio JJ: Oleanolic acid, a compound present in grapes and olives, protects against genotoxicity in human mammary epithelial cells. Molecules 20: 13670-13688, 2015.

69. Sasikumar K, Dubey V and Ghosh AR: Oleanolic acid from black raisins, Vitis vinifera with antioxidant and antiproliferative potentials on HCT 116 colon cancer cell line. Braz J Pharm Sci 56: 56, 2020 .

70. Hu M and Polyak K: Microenvironmental regulation of cancer development. Curr Opin Genet Dev 18: 27-34, 2008.

71. Nishida N, Yano H, Nishida T, Kamura T and Kojiro M: Angiogenesis in cancer. Vasc Health Risk Manag 2: 213-219, 2006.

72. Rajabi M and Mousa SA: The role of angiogenesis in cancer treatment. Biomedicines 5: 34, 2017.

73. Caunii A, Oprean C, Cristea M, Ivan A, Danciu C, Tatu C, Paunescu V, Marti D, Tzanakakis G, Spandidos DA, et al: Effects of ursolic and oleanolic on SK-MEL-2 melanoma cells: In vitro and in vivo assays. Int J Oncol 51: 1651-1660, 2017.

74. Sogno I, Vannini N, Lorusso G, Cammarota R, Noonan DM, Generoso L, Sporn MB and Albini A: Anti-angiogenic activity of a novel class of chemopreventive compounds: oleanic acid terpenoids. Recent Results Cancer Res 181: 209-212, 2009.

(i) $(-)$ This work is licensed under a Creative Commons Attribution-NonCommercial-NoDerivatives 4.0 International (CC BY-NC-ND 4.0) License. 